\title{
Multicriteria-based methodology for the design of rural electrification systems. A case study in Nigeria
}

\author{
M. Juanpera ${ }^{1,2}{ }^{*}$, P. Blechinger ${ }^{4}$, L. Ferrer-Martí ${ }^{1,3}$, M.M. Hoffmann ${ }^{4}$, R. Pastor ${ }^{1,2}$ \\ 1. Institute of Industrial and Control Engineering, Universitat Politècnica de Catalunya - BarcelonaTech (Spain) \\ 2. Department of Management, Universitat Politècnica de Catalunya - BarcelonaTech, (Spain) \\ 3. Department of Mechanical Engineering, Universitat Politècnica de Catalunya - BarcelonaTech, (Spain) \\ 4. Reiner Lemoine Institut, Berlin (Germany) \\ *Corresponding author details: marc.juanpera@upc.edu
}

\begin{abstract}
Electrification with micro-grids is receiving increasing attention to electrify rural areas in developing countries. However, determining the best local supply solution is a complex problem that requires considering different generation technologies (i.e. solar PV, wind or diesel) and different system configurations (off-grid or on-grid). Most existing decision aid tools to assess this design only consider economical and technical issues in a single optimization process. However, social and environmental considerations have been proven key issues to ensure long-term sustainability of the projects. In this context, the objective of this work is to develop a multicriteria procedure to allow comparing electrification designs with on-grid or isolated micro-grids and different technologies considering multiple aspects. This multicriteria procedure is integrated in a two-phased methodology to assist the design of the system to electrification promoters in a structured process. First, different electrification alternatives are generated with an open-source techno-economic optimization model; next, these alternatives are evaluated and ranked with the multicriteria procedure, which considers 12 criteria representing economic, technical, socio-institutional and environmental aspects. The whole design methodology is validated with a real case study of 26 population settlements in Plateau State, Nigeria. Experts in rural electrification within the Nigerian context have been consulted to weight the criteria and particularize their evaluation for the specific case study. Results show that solar PV technology based systems are the most suitable electrification designs for communities in Nigeria, while grid connection feasibility depends on the size of the community and the distance to the closest national grid consumption point.
\end{abstract}

\section{Highlights}

- Rural electrification designs are compared with a multicriteria procedure.

- Economic, technical, social and environmental aspects are considered.

- The procedure is validated with a case study of 26 communities in Nigeria.

- Experts in rural electrification have been contacted to weight the criteria.

- Final results recommend PV technology-based systems.

Key words: Rural electrification, design methodology, multicriteria procedure, case study

Word count: 9377 words 


\section{INTRODUCTION}

Nowadays, around 850 million people do not have electricity access [1], mainly living in rural and remote areas [2]. The conventional strategy to expand electricity access is extending the national grid [3]. However, significant techno-economic constraints can appear in mountainous or remote areas, due to the hilly terrain, scattered communities and low consumption levels [3]. Moreover, individual systems are a cheap and easy electrification option but may arise inequalities within the community and cannot be adapted to potential increases on demand [4]. Alternatively, electrification systems based on micro-grids (MGs) are receiving increased attention, as they provide a greater equity and flexibility in consumption, and cost savings through economies of scale $[5,6]$.

MGs are capable of operating in both stand-alone (off-grid) and grid-connected (on-grid) modes [7,8]. On the one hand, off-grid MGs aim to improve life's quality of people living in areas for which an extension of the national grid could take too much time and is not economic affordable [9]. Differently, if the aforementioned constraints for national grid extension are overcome, on-grid MGs ensure an improvement on reliability and resilience of supply [9], as well as potential electricity exchanges with the main grid that can lead to reductions in the total costs and, consequently, to a more likely economic viability of the electrification project [10].

Regarding the technologies of electricity generation within the MGs, wind and solar photovoltaic (PV) technologies are increasingly used since they are available worldwide [11,12]. In particular, hybrid windPV systems are interesting, as they can complement each other and reduce project costs while increasing supply quality $[2,13]$. Despite the growth in hybrid wind-PV systems worldwide, most rural electrification projects in Africa are still based on diesel generators [14]. In fact, in order to achieve universal access to electricity in 2030 [15], the use of diesel technology within the poorest regions of developing countries is expected to grow $[16,17]$.

Therefore, rural electrification planning should take into account scenarios that combine different electricity distribution options (national grid extension and decentralized off-grid systems) with different technologies of electricity generation: renewable and non-renewable [18]. There are several tools able to consider such scenarios and generate electrification alternatives through techno-economic optimization methods. Among all of them, HOMER [19] and ViPOR [20] are widely used in developing countries. In particular, HOMER considers many technologies and designs the generation system meticulously, while ViPOR focuses on distribution scheme planning [21]. Also, open-source tools have been developed for techno-economic optimization and simulation of energy systems, such as OSeMOSYS [22] and, more recently and with greater focus on mini-grids and Solar Home Systems, Offgridders [23].

However, the aforementioned tools only take into account technical and economic issues to identify the best electrification system design for rural locations, which proved to be insufficient to ensure long-term sustainability of the project $[24,25]$. Additional factors are being considered relevant, such as: adequate policy prescription [26], wide institutional support to electricity programs through solid regulation and incentives to private investment [27] and inclusion of final electricity users' opinions in the design process 
[21]. In consequence, recently studies have included other dimensions in the evaluation processes of rural electrification systems. Some examples consider five dimensions (technical, economical, ethicsocial, environmental and institutional) to define respective sustainable evaluation methodologies [2830]; while López-González et al. [31] propose four dimensions for the design and evaluation of rural electrification programs: environmental, technical, socioeconomic and institutional.

Introducing new dimensions next to the economic and technical increases the complexity of the projects' design process [21]. Therefore, a two-phased process constitutes an easy-to-follow structure [32]: in phase 1, electrification alternatives are generated using optimization processes; and in phase 2, the best alternative is selected using multicriteria techniques. Thus, a great accuracy is obtained in the problem optimization and the decision-making process gets easier since the potential solutions and their performance is known before deciding [21,33].

Already some two-phased tools have been designed to assist decision-making in rural electrification problems. For example, OptEIDec [34] sizes several technologies to supply electricity to isolated MGs and selects the best one according to their performance on some criteria. Other similar tools also allow combining different technologies, such as SURE [35], and offer a high detail of the final distribution scheme, such as the methodology proposed in Domenech et al. [21]. However, none of these tools consider the possible extension of the national grid when sizing the equipment and selecting the best alternative.

In this context, this research aims to develop a multicriteria procedure to select the best electrification design from different ones considering both on-grid and isolated MGs and combining different technologies for electricity generation. This multicriteria procedure is integrated in a two-phased methodology capable of designing rural electrification systems in a structured process that takes into account multiple aspects. First, electrification alternatives are generated with a techno-economic optimization model. Then, the best alternative is selected based on their performance in 12 criteria grouped into four dimensions: economic, technical, socio-institutional and environmental. These criteria have been defined specifically to allow comparing electrification designs which might consider national grid extension and different generation technologies, and are particularized for each case study based on experts' opinions. The resulting methodology is expected to assist decision and policy makers in this complex process of determining the best electrification design within an integral approach. Also, Its performance is finally validated with a real case study of 26 population settlements in Nigeria.

The rest of the paper is organized as follows. In section 2, a quick overview of the two-phased methodology is realized. Sections 3 and 4 deepen the description of the methodology focusing on how alternatives are generated (section 3) and how are evaluated and ranked (section 4). Section 5 applies the methodology to a case study of 26 communities in Nigeria and selects the best electrification alternative for each one. Finally, in section 6 conclusions of the work are summarized and future lines of research are mentioned. 


\section{METHODOLOGY FOR THE DESIGN OF RURAL ELECTRIFICATION SYSTEMS}

Rural electrification is a multidimensional problem [36] that involves a great variety of stakeholders [37]: from the target group to local industries and non-governmental organizations. Each stakeholder has its particular needs and expectations [38,39] which should be fulfilled with the planned electrification program to ensure long-term sustainability. Therefore, decisions based exclusively on economic and technical issues lack on the interdisciplinary approach needed in the design of an electrification project [40].

Tools for electrification planning usually focus only on the economic and technical side, forgetting or considering with lower detail social and environmental consequences of the system design. In this context, this study utilizes a two-phased design methodology (Figure 1) which combines technoeconomic optimizations of different electrification scenarios with a multicriteria evaluation within a holistic procedure to enable the selection of the best design considering multiple aspects.

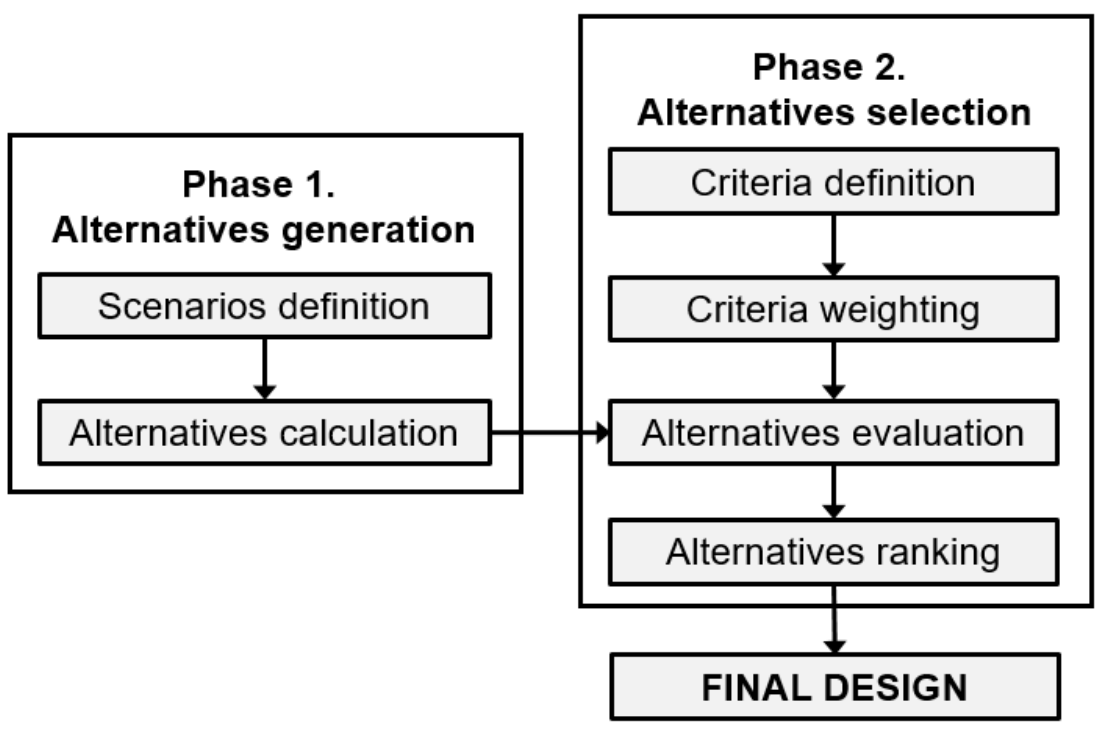

Figure 1. Methodology followed for the design of electrification systems

In phase 1, different electrification designs are obtained using a techno-economic optimization model. This phase requires a definition of scenarios that may differ in the technologies considered for electricity generation and in the possible connection of the MGs to the national grid. In detail, on-grid and off-grid scenarios are considered, with PV, diesel and wind as generation technologies within the MGs. Then, an electrification alternative is obtained from each scenario using an optimization process aimed at minimizing the annual cost of the electrification project while ensuring technical viability. This phase, and particularly the optimization model used, is further described in section 3.

In phase 2, a multicriteria analysis is designed to evaluate and rank the alternatives in order to allow a justified selection of the best design for each community. Based on similar analysis in the literature, it 
follows a four-points structure [41]. First, a set of appropriate criteria is defined. These criteria are then weighted in order to establish their relative importance $[42,43]$. Next, the electrification alternatives generated in phase 1 are evaluated according to each criterion by assigning a score to each pair criterionalternative. Finally, a global score for each alternative is calculated by aggregating all evaluation results considering criteria weights. These global scores define the ranking of alternatives and help to identify the best overall alternative. This phase's procedure for the problem addressed is presented and further described in section 4.

\section{GENERATION OF ELECTRIFICATION ALTERNATIVES}

The electrification alternatives are generated in phase 1 with the optimization model of Offgridders, which consider technical and economic constraints. This is an open-source tool [23] able to first define electrification scenarios by defining the needed assets: i.e. a PV plant, a wind farm or diesel generators. Then, the corresponding alternatives are generated by sizing these assets through a techno-economic optimization process. It is based on the Open Energy Modelling Framework (oemof) [44], which allows modelling any energy system (electrification scenarios in this case), using a graph approach. Thus, the energy graph is the representation of the electricity scenario in graph format.

Following the design methodology represented in Figure 1, the section is divided into two subsections. These subsections aim to describe how scenarios are defined in graph format (3.1) in order to later calculate the corresponding alternatives with an extended formulation of the optimization model (3.2).

\subsection{Scenarios definition}

In this study, electrification scenarios that include different system configuration options (off-grid and ongrid) and a variety of technologies of electricity generation (solar PV, wind and diesel) are defined. For each scenario, an energy graph is built. As an example, Figure 2 shows the energy graph (Figure 2b) equivalent to an on-grid scenario based on $\mathrm{PV}$, wind and diesel generators (schematically represented in Figure 2a). As it is shown in Figure 2a, the electricity distribution network within the community is assumed to be based on a single micro-grid (MG). This MG consists of two electricity buses to supply alternating current (AC) demand and direct current (DC) demand from the respective technologies of electricity generation: PV, wind, diesel and the national grid. While PV and wind generation are determined by weather forecasts, diesel and the national grid are considered unlimited sources for the optimization. Therefore, unlike PV and wind generation, a transformer is considered in the energy graph for the diesel source and the national grid to limit electricity supply in those cases. Both the demand and the weather forecasts are determined by time-series data, detailing the hourly power demand of a community and the solar and wind potential, respectively, during the optimization time. 


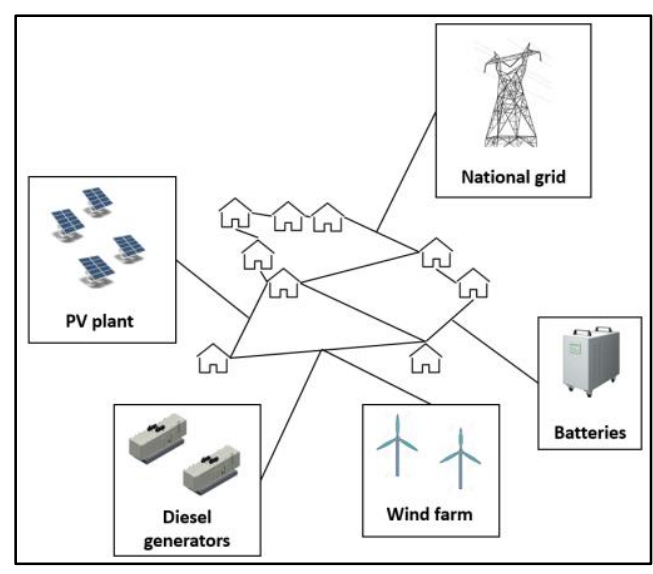

Figure $2 a$

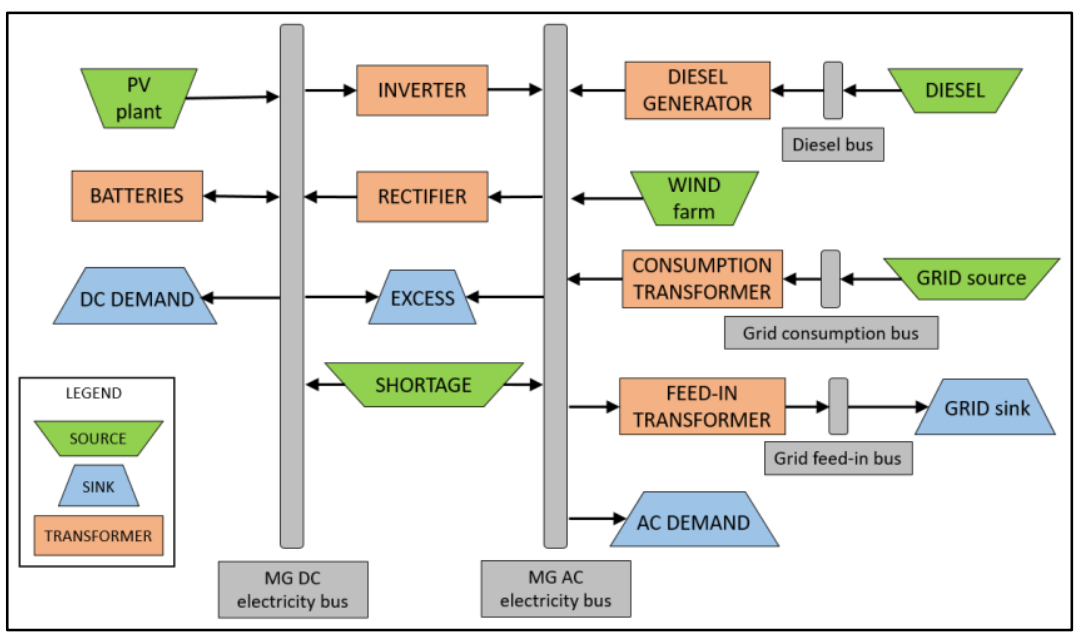

Figure $2 b$

Figure 2. Scheme of an on-grid electrification scenario based on PV, wind and diesel sources (a) and equivalent energy graph (b)

Additionally, batteries are considered to store energy in DC, while inverters and rectifiers convert energy from one bus to the other. The national grid is modelled with two transformers for electricity consumption and feed-in. Finally, extra symbolic components are also included in the model, such as an excess sink and a shortage source. On the one hand, the excess sink is necessary to vent energy in those time steps when renewable generation is higher than demand. On the other hand, the shortage source works as a fake source to balance out potential shortage on supply. Also, this fake source can be used to intentionally avoid fulfilling demand completely by defining a maximum shortage level allowed. Small shortage levels on annual supply (around 5\%) permit not to dimension the energy assets for a particularly bad day, which might significantly reduce investment costs.

\subsection{Alternatives calculation}

To generate the electrification alternatives, each scenario represented with an energy graph is solved through an optimization model that aims to minimize the total cost of the project for the electrification scenario established. The alternatives obtained are characterized by the cost and size of the electrification equipment. In particular, the multicriteria procedure in phase 2 uses the economic outputs, the optimal power capacities and the optimal dispatch at each hour of the optimization time to evaluate the electrification alternatives.

Offgridders' optimization model has been developed in Hoffmann [45] and used to solve scenarios that include both off-grid and on-grid scenarios with electricity generation based on only solar PV and diesel generators [46,47]. Beyond the essential technical constraints, an additional constraint has been formulated to force battery charge as soon as extra electricity is available [45]. Now, to ease a complete understanding of the alternatives evaluation and ranking described in section 4 , an extended formulation 
of the model (version 3.1) is presented to solve the scenario described in Figure 1, which also includes wind technology. Moreover, this extended formulation includes additional constraints to allow small shortages on annual demand and to ensure a certain amount of demand can be supplied at any time by weather-independent sources (diesel and the national grid) and the energy stored in the batteries.

\section{Data:}

- Indices.

$i$

$t \in\{0,1, \ldots T\}$ assets included in the electrification scenario. This scenario includes: solar PV plant (S), wind farm $(W)$, diesel source $(F U)$, diesel generators $(D)$, batteries $(B)$, inverter $(I)$, rectifier $(R)$, grid source and grid sink $(G)$, consumption transformer $(C)$, feed-in transformer $(F)$, shortage (SH) and excess (E).

hourly time step (h). $T$ is the time horizon of the optimization, usually one year (8640 h).

- Economic data.

$\begin{array}{ll}I n v_{i} & \text { investment costs for an installation of asset } i(\$ / \mathrm{kW}), i \in\{W, D, B, I, R, C, F\} \\ I n v_{S} & \text { investment costs for an installation of the solar PV plant }(\$ / \mathrm{kWpeak}) \\ t a_{i} & \text { lifetime of asset } i(\mathrm{y}), i \in\{S, W, D, B, I, R, C, F\} \\ t n & \text { lifetime of the project } \\ \text { Opex }_{i} & \text { specific fixed operational expenditure of asset } i(\$ / \mathrm{kW} / \mathrm{y} \text { or } \$ / \mathrm{kWpeak} / \mathrm{y}), \\ & i \in\{S, W, D, B, I, R, C, F\} \\ \text { Cvar }_{i} & \text { variable dispatch costs of asset } i(\$ / \mathrm{kWh}), i \in\{S, W, D, B, I, R, C, F, S H, E\} \\ p_{D} & \text { diesel price }(\$ / l) \\ p_{C} & \text { grid consumption tariff }(\$ / \mathrm{kWh}) \\ p_{F} & \text { grid feed-in tariff }(\$ / \mathrm{kWh})\end{array}$

- Aggregated demand profiles of the community.

$D A C_{t} \quad$ AC power demand in time step $t(\mathrm{~kW})$

$D D C_{t} \quad$ DC power demand in time step $t(\mathrm{~kW})$

- Solar and wind generation forecasts in the community.

$E S_{t} \quad$ solar potential in the community, related to the peak power, in time step $t(\mathrm{~kW} / \mathrm{kWpeak}$.)

$E W_{t} \quad$ wind potential in the community, related to the maximum generation available, in time step $t$ (kWh/kWhmax.)

- Technical data of the assets.

$a v_{t}: \quad \quad$ national grid availability, with 1 indicating availability and 0 indicating a blackout for each time step $t$.

$\eta_{i} \quad$ efficiency of asset $i$ (factor), $i \in\{D, I, R, C, F\}$

$\eta_{\text {in }} \quad$ inflow conversion factor into the batteries (factor)

nout $_{B} \quad$ outflow conversion factor from the batteries (factor)

$\varepsilon \quad$ loss rate in the batteries during a time step (factor)

SOCmin minimum state of charge of the batteries (factor)

SOCmax maximum state of charge of the batteries (factor)

Cratein investment relation between power inflow and batteries' capacity within time step $t$ (factor)

Crateout investment relation between batteries' capacity and power outflow within time step $t$ (factor) 
- Additional data to add constraints, if desired:

$U_{S H}$

$S$ maximum allowed shortage of annual energy supplied related to annual demand (factor). 0 if no shortage is allowed.

factor of demand that weather-independent sources can ensure to supply in each time step $t$ (factor). 0 if demand could be completely fulfilled equally by weather-dependent and weather-independent sources.

Decision variables: non-negative real variables are used to define the power capacities of the assets and the power flows during each time step.

\begin{tabular}{|c|c|}
\hline$C_{i}$ & power capacity of asset $i(\mathrm{~kW}), i \in\{W, D, B, I, R, C, F\}$ \\
\hline$C A P_{S}$ & power capacity the solar PV plant (kWpeak) \\
\hline FtoAC $C_{i, t}$ & power flow from asset $i$ to electricity AC bus (kW), $i \in\{W, D, I, C, S H\}$ \\
\hline FACto $_{i, t}$ & power flow from electricity $\mathrm{AC}$ bus to asset $i(\mathrm{~kW}), i \in\{R, F, E\}$ \\
\hline FtoDC $C_{i, t}$ & power flow from asset $i$ to electricity DC bus (kW), $i \in\{S, B, R, S H\}$ \\
\hline$F D C t o_{i, t}$ & power flow from electricity $\mathrm{DC}$ bus to asset $i(\mathrm{~kW}), i \in\{B, I, E\}$ \\
\hline Ftof $u_{F U, t}$ & power flow from diesel source to diesel bus (kW) \\
\hline Ffuto $_{D, t}$ & power flow from diesel bus to diesel generator $(\mathrm{kW})$ \\
\hline$F \operatorname{tog} c_{G, t}$ & power flow from national grid to grid consumption bus $(\mathrm{kW})$ \\
\hline Fgcto $_{C, t}$ & power flow from grid consumption bus to grid consumption transformer (kW) \\
\hline Ftog $f_{F, t}$ & power flow from grid feed-in transformer to grid feed-in bus (kW) \\
\hline$F g$ fto $_{G, t}$ & power flow from grid feed-in bus to national grid $(\mathrm{kW})$ \\
\hline$P B_{t}$ & state of charge of the batteries $(\mathrm{kW})$ \\
\hline
\end{tabular}

Objective function: The objective function minimizes the annual costs of the project, considering capital and operational expenditures related to asset's installation and system operation. Annual costs of each asset $\left(a_{i}\right)$ are calculated in a pre-processing step considering capital and operational expenditures $\left(\right.$ Capex $_{i}$ and Opex $_{i}$ ) (eq. 1). Capital expenditures take into account necessary replacements for each asset $\left(n_{i}\right)$ and its remaining value at the end of the project lifetime $\left(R V_{i}\right)$ (eqs. 2-4). Finally, the capital recovery factor $\left(C R F_{i}\right)$ is calculated as usual based in the appropriate discount factor $(d)$ (eq. 5).

$$
\begin{gathered}
a_{i}=\text { Capex }_{i} \cdot C F_{i}+\text { Opex }_{i} \\
\text { Capex }_{i}=\sum_{m=0}^{n_{i}} \frac{i n v_{i}}{(1+d)^{m \cdot t a_{i}}}-R V_{i} \\
R V_{i}=\frac{\frac{i n v_{i}}{(1+d)^{\left(n_{i}-1\right) \cdot t a_{i}}}}{t a_{i}} \cdot\left(\left(n_{i}+1\right) \cdot t a_{i}-t n\right) \\
n_{i}=\text { round }\left(\frac{t n}{t a_{i}}+0.5\right)-1
\end{gathered}
$$




$$
C R F_{i}=\frac{d \cdot(1+d)^{t a_{i}}}{(1+d)^{t a_{i}-1}}
$$

The objective function is then defined as following (eq.6):

$$
\begin{aligned}
{[\min ] z=} & \sum_{i \in\{S, W, D, B, I, R, C, F\}} a_{i} \cdot C A P_{i} \\
& +\sum_{\forall t}\left[\sum_{i \in\{S, S H\}} \operatorname{Cvar}_{i} \cdot F t o D C_{i, t}+\sum_{i \in\{W, D, S H\}} \operatorname{Cvar}_{i} \cdot F t o A C_{i, t}+\left[p_{D} \cdot F t o f u_{F U, t}+p_{C} \cdot F t o g c_{G, t}-p_{F} \cdot F g f t o_{G, t}\right]\right]
\end{aligned}
$$

Constraints: Constraints (eq. 7) force the electricity AC and DC buses, as well as the diesel bus, the grid consumption bus and the grid feed-in bus to be balanced. Constraints (eq. 8) considers the conversion efficiency of the transformer components. Constraints (eq. 9) fix the power generation flow of the PV plant and the wind farm according to the generation potential and the optimized capacity of each asset. Constraints (eq. 10) avoid power flows to exceed the limit set by the capacity of each asset. In particular, the input and output power flow of the battery are limited by the corresponding investment relations. Constraints (eq. 11) define how the state of charge of the batteries is modified through the optimization time. In detail, a steady state behaviour is stablished and the state of charge is comprised between a minimum and a maximum storage level. Constraint (eq. 12) uses the fake shortage source to limit the acceptable amount of shortage on annual demand. Finally, constraints (eq. 13) ensure a certain amount of demand can be supplied by sources that do not depend on weather conditions.

$$
\begin{aligned}
& \sum_{i \in\{W, D, I, C, S H\}} F t o A C_{i, t}-\sum_{i \in\{R, F, E\}} F A C t o_{i, t}=D A C_{t} \quad \forall t \\
& \sum_{i \in\{S, B, R, S H\}} F t o D C_{i, t}-\sum_{i \in\{B, I, E\}} F D C t o_{i, t}=D D C_{t} \quad \forall t \\
& \text { Ftofu }_{F U, t}-\text { Ffuto }_{D, t}=0 \quad \forall t \\
& \text { Ftogc }_{G, t}-\text { Fgcto }_{C, t}=0 \quad \forall t \\
& \text { Ftogf }_{F, t}-\text { Fgfto }_{G, t}=0 \quad \forall t \\
& \text { FtoAC }_{D, t}-\eta_{D} \text { Ffuto }_{D, t}=0 \quad \forall t \\
& \text { FtoDC }_{R, t}-\eta_{R} \text { FACto }_{R, t}=0 \quad \forall t \\
& \text { FtoAC }_{I, t}-\eta_{I} \text { FDCto }_{I, t}=0 \quad \forall t \\
& \text { FtoAC }_{C, t}-\eta_{C} \text { F gcto }_{C, t}=0 \quad \forall t \\
& \text { Ftogf }_{F, t}-\eta_{F} \text { FACto }_{F, t}=0 \quad \forall t \\
& F t o D C_{S, t}-E S_{t} C A P_{s}=0 \quad \forall t \\
& \text { FtoAC }_{W, t}-E W_{t} C A P_{W}=0 \quad \forall t
\end{aligned}
$$




$$
\begin{aligned}
& \text { FtoAC }_{D, t}-\text { CAP }_{D} \leq 0 \quad \forall t \\
& \text { FACto }_{R, t}-C A P_{R} \leq 0 \quad \forall t \\
& \text { FDCto }_{I, t}-C A P_{I} \leq 0 \quad \forall t \\
& \text { FtoAC }_{C, t}-C A P_{C} \cdot a v_{t} \leq 0 \quad \forall t \\
& \text { Ftogf }_{F, t}-C A P_{F} \cdot a v_{t} \leq 0 \quad \forall t \\
& \text { FDCto }_{B, t}-\text { Cratein } \cdot \text { CAP }_{B} \leq 0 \quad \forall t \\
& \text { FtoDC }_{B, t}-\text { Crateout } \cdot C A P_{B} \leq 0 \quad \forall t \\
& P B_{t}=P B_{t-1} \cdot(1-\varepsilon)+\eta \operatorname{in}_{B} \cdot F D C t o_{B, t}-\frac{F t o D C_{B, t}}{\eta \operatorname{in}_{B}} \quad \forall t \\
& P B_{0}=P B_{T} \quad \forall t \\
& \mathrm{SOCmin} \cdot \mathrm{CAP}_{B} \leq P B_{t} \leq \mathrm{SOCmax} \cdot \mathrm{CAP}_{B} \quad \forall t \\
& \sum_{\forall t} F t o D C_{S H, t}+\sum_{\forall t} F t o A C_{S H, t} \leq \mathrm{U}_{S H} \cdot\left(\sum_{\forall t} D D C_{t}+\sum_{\forall t} D A C_{t}\right)
\end{aligned}
$$

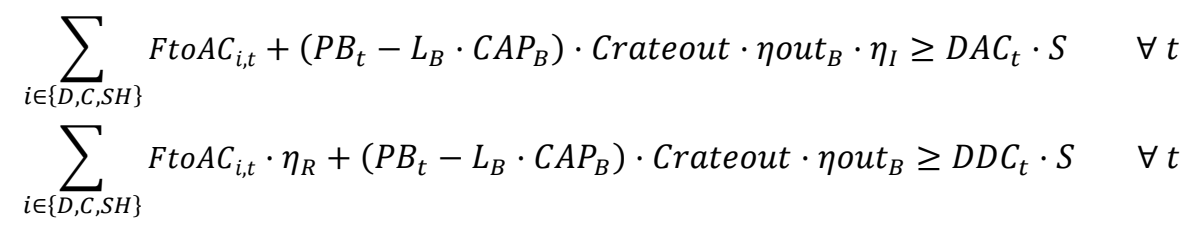

\section{SELECTION OF ELECTRIFICATION ALTERNATIVES}

Multicriteria analysis is a useful technique to select the best electrification alternative, since multiple aspects can be introduced into the decision process. Therefore, it is designed and used in this second phase to evaluate and rank the electrification alternatives obtained in phase 1 after techno-economic optimizations of different scenarios. This multicriteria procedure allows, thus, to include social, institutional and environmental aspects, apart from economic and technical ones, into the electrification systems design. This section is also organized following the design procedure detailed in Figure 1. First (4.1), some appropriate criteria are defined. Then (4.2), the weighting method for these criteria is presented. Next (4.3), the evaluation procedure of the alternatives is defined for each criterion. Finally (4.4), the compromise ranking method used to rank the alternatives is described.

\subsection{Criteria definition}

To evaluate alternatives that differ in the technologies used for electricity generation within the MG (PV, wind, diesel) and the system configuration (on-grid or off-grid), 12 criteria have been defined and 
classified in four dimensions: economic, technical, socio-institutional and environmental. The next paragraphs focus on defining both dimensions and criteria.

The economic dimension evaluates the economic impact of the project throughout its lifetime. Its evaluation in this study is divided into two criteria: the initial costs needed to put the system into operation and the annual balance between required costs for regular operation and maintenance and potential revenues. Next, the two criteria are described.

Initial investment (EC-1): capital costs needed to set up the project. All upfront costs related to the purchase of mechanical equipment, technological installations, construction of facilities and engineering services are included in this criterion.

Operation and maintenance, O\&M, balance (EC-2): annual difference between costs paid during the project lifetime to operate and maintain the electrical equipment and revenues for electricity feed-in to national grid. Expenditures such as diesel supply and costs for electricity consumption from the grid are also included.

The technical dimension evaluates the system performance and is related to the accomplishment of global access to reliable energy [15,31]. Its evaluation in this study is divided into four criteria: the autonomy factor, the existence of annual shortages on demand, the reliability of supply against weather variability or the likelihood of equipment failure. Next, the four criteria are described.

Autonomy factor (T-1): share of electricity supplied from MG sources (solar PV, wind or diesel) compared to total electricity supplied. Local electricity generation instead of grid consuming allows a lower dependence on external factors that can negatively affect electricity supply.

Complete fulfillment of demand (T-2): ratio of the annual energy supplied compared to annual demand, as initial computational experiments have shown that small shortages on annual supply (around 2-5\%) induce in significant reductions of investment costs (5-15\%). This criterion balances the influence of a reduction in investment costs at the expense of not supplying $100 \%$ of demand, and is directly connected to the value for the maximum shortage specified for the optimization.

Reliability of generation sources ( $T$-3): expectation that a power system meets the load requirements at any time [48] according to the forecasted generation profiles. Factors such as weather variability can slightly modify solar and wind forecasts, while deficient infrastructures can provoke delays in diesel supply.

Equipment failure (T-4): likelihood of equipment failure due to technical, mechanical or external issues such as extreme meteorological phenomena (high temperatures, strong wind or high precipitations). Technical and mechanical failures may be caused by inappropriate design, use of unreliable components, improper installation or poor maintenance [49], and usually affect differently each technology of electricity generation [50]. 
The socio-institutional dimension evaluates the social impact of the project into the communities from a local and a global perspective. In particular, its evaluation in this study is divided into three criteria: the tariff required to be pay by end-users for the electrical service, the users' acceptance of the different technologies of electricity generation and the institutional alignment of the system design with national trend. Next, the three criteria are described.

Tariff for electrical service (S-1): mean amount of money that end-users pay each month for the electrical service. This rate can be free, periodic or according to consumption [51], and determinates the direct economic consequences of the project to end-users. The tariff depends on the regulation market of the country where the project is implemented and must be calculated based on appropriate information of the country.

Users acceptance (S-2): acceptability of the different technologies of electricity generation. If the electrification alternative does not fit into the sociocultural context of the community, it may provoke resistance and difficult the project success [25]. Oppositely, good opinions on one generation source, e.g. due to former experiences, can positively affect its implementation.

Institutional alignment (S-3): alignment of the generation sources with the government's national trend. Subsidies or other eco-political benefits are easier to obtain if the selected technologies fit well with the government strategy for rural electrification.

The environmental dimension evaluates the climate impact of the project and comprehends all project activities influencing the local ecosystems as well as the natural resources of the electrified area [28,31]. Its evaluation in this study is divided into three criteria: $\mathrm{CO}_{2}$ emissions due to electricity generation, impact on population due to visual, noise and land-use concerns and wastes of components at the end of their lifetime. Next, the three criteria are described.

$\mathrm{CO}_{2}$ emissions (EN-1): tones of $\mathrm{CO}_{2}$ emitted by the electrical system. PV and wind sources are assumed to be completely without emissions, while the emission factor for diesel generators is set to $0.77 \mathrm{kgCO}_{2}$ per kWh of electricity produced [17]. An emission factor for the main grid must be specifically calculated for the country of application.

E-Impact on population (EN-2): negative effects on local population due to visual impact, noise and land-use as a result of the installation and operation of the electrical equipment.

Wastes of components (EN-3): wastes generation at the end of the components lifetime, considering which percentage of them allow recycle or reuse and how easy each decommission is. This issue is particularly tricky for batteries [52], so it can indirectly affect wind and solar PV technologies.

\subsection{Criteria weighting}


Once the dimensions and criteria are defined, they are weighted by assigning a value to each dimension and each criterion. This value represents its importance in relation to the others and must be particularized for each project according to the opinion of local experts in the field of rural electrification. Therefore, the results of the weighting for the case study can be found in section 5.2 and are based on the questionnaire sent to local experts attached in Appendix A. In detail, the final weight of each criterion $\left(w_{i j}\right)$ and dimension $\left(w_{j}\right)$ is calculated as following (eq. 14):

$$
w_{i j}=\frac{\sum_{k=1}^{n} \frac{r_{i j k}}{\sum_{i^{\prime}=1}^{m_{j}} r_{i^{\prime} j k}}}{n} \quad w_{j}=\frac{\sum_{k=1}^{n} \frac{\sum_{i=1}^{m_{j}} \frac{r_{i j k}}{m_{j}}}{\sum_{j^{\prime}=1}^{d} \sum_{i=1}^{m_{j^{\prime}}} \frac{r_{i j^{\prime} k}}{m_{j^{\prime}}}}}{n}
$$

Where $r_{i j k}$ is the importance rating given by expert $k$ to criterion $i$ belonging to dimension $j$ (obtained with questionnaire in appendix $\mathrm{A}) ; m_{j}$ is the number of criteria attached to dimension $j ; n$ is the number of experts asked and $d$ is the number of dimensions.

\subsection{Alternatives evaluation}

As structured in Figure 1, once the electrification alternatives are generated (phase 1) and the criteria are defined and weighted (first two steps of phase 2), the evaluation procedure can start. This is based on indicators which evaluate the fulfillment of the corresponding criteria by considering the outputs of the optimization; in particular, the investment costs and operational expenditures required, the assets' optimal capacities and the optimal power flows during the optimization time (Table 1). As a result, a perfect integration of alternatives generation and selection phases can be achieved.

Since both qualitative and quantitative criteria have been defined, the evaluation of the qualitative ones (i.e. robustness of supply, users' acceptance or impact on population) requires a prior assessment. In this assessment, punctuations are given to the performance of the different options of electricity generation (PV, wind, diesel and the national grid) according to each criterion in discussion. These punctuations are used to calculate a weighted average ratio of electricity generation (for T-3, T-4, S-2, S3 ) or optimized power capacity (for EN-2, EN-3) from the different technologies. Similar to the criteria weighting, such punctuations must be discussed for each project among a group of experts. Thus, the results of this assessment are presented in section 5.2 and are based on the questionnaire attached in Appendix B.

Table 1. Dimensions, criteria and indicators for the multicriteria procedure of electrification alternatives

\begin{tabular}{|l|l|l|l|l|c|}
\hline Dimension & \multicolumn{2}{|l|}{ Criteria } & $(+/-)$ & Indicator & Units \\
\hline Economic & EC-1 & Initial investment & - & $\begin{array}{l}\text { Sum of all investments costs, including main grid extension } \\
\text { and costs within the MG. }\end{array}$ & $\mathrm{m} \$$ \\
\hline
\end{tabular}




\begin{tabular}{|c|c|c|c|c|c|}
\hline & EC-2 & O\&M balance & - & $\begin{array}{l}\text { Sum of all costs related to operation and maintenance of } \\
\text { equipment and diesel and grid consumption expenditures. } \\
\text { They include also revenues for feed-in to main grid. }\end{array}$ & $\mathrm{m} \$ / \mathrm{y}$ \\
\hline \multirow{4}{*}{ Technical } & $\mathrm{T}-1$ & Autonomy factor & + & $\begin{array}{l}\text { Percentage of electricity generated locally within the MG (due } \\
\text { to renewable sources or diesel generators) vs all electricity } \\
\text { generated. }\end{array}$ & $\%$ \\
\hline & T-2 & $\begin{array}{l}\text { Complete fulfilment } \\
\text { of demand }\end{array}$ & + & Percentage of annual electricity supplied vs annual demand. & $\%$ \\
\hline & T-3 & $\begin{array}{l}\text { Reliability of } \\
\text { generation sources }\end{array}$ & + & $\begin{array}{l}\text { Weighted average sum of the electricity generated by each } \\
\text { technology (weighted by qualitative punctuations given). }\end{array}$ & factor \\
\hline & $\mathrm{T}-4$ & Equipment failure & + & $\begin{array}{l}\text { Weighted average sum of the electricity generated by each } \\
\text { technology (weighted by qualitative punctuations given). }\end{array}$ & factor \\
\hline \multirow{3}{*}{$\begin{array}{l}\text { Socio- } \\
\text { institutional }\end{array}$} & S-1 & $\begin{array}{l}\text { Tariff for electrical } \\
\text { service }\end{array}$ & - & $\begin{array}{l}\text { Mean amount of money an habitant of a community must pay } \\
\text { monthly, based on country regulations regarding electrical } \\
\text { tariff for grid service and MGs. }\end{array}$ & $\begin{array}{c}\$ / \\
k W h\end{array}$ \\
\hline & S-2 & Users acceptance & + & $\begin{array}{l}\text { Weighted average sum of the electricity generated by each } \\
\text { technology (weighted by qualitative punctuations given). }\end{array}$ & factor \\
\hline & S-3 & $\begin{array}{l}\text { Institutional } \\
\text { alignment }\end{array}$ & + & $\begin{array}{l}\text { Weighted average sum of the electricity generated by each } \\
\text { technology (weighted by qualitative punctuations given). }\end{array}$ & factor \\
\hline \multirow{3}{*}{ Environmental } & EN-1 & $\mathrm{CO}_{2}$ emissions & - & $\begin{array}{l}\text { Tones of } \mathrm{CO}_{2} \text { emitted due to the diesel generators or the } \\
\text { electrical national grid. }\end{array}$ & tons \\
\hline & EN-2 & $\begin{array}{l}\text { E-Impact on } \\
\text { population }\end{array}$ & + & $\begin{array}{l}\text { Weighted average sum of the optimized power capacity of } \\
\text { each technology (weighted by qualitative punctuations given) }\end{array}$ & factor \\
\hline & EN-3 & $\begin{array}{l}\text { Wastes of } \\
\text { components }\end{array}$ & + & $\begin{array}{l}\text { Weighted average sum of the optimized power capacity of } \\
\text { each electrical component (weighted by qualitative } \\
\text { punctuations given) }\end{array}$ & factor \\
\hline
\end{tabular}

\subsection{Alternatives ranking}

The aggregation of the evaluation results can vary according to the multicriteria technique used. This study utilizes the compromise ranking method, due to its proven effectiveness in energy applications in rural areas. In detail, it has been applied to design low-scale electrification systems [21] and biogas digesters for rural areas $[43,53]$. This method consists of comparing each alternative to an ideal solution, which is an utopian solution that performs optimally for all criteria $[54,55]$. The closest alternative to the ideal solution is then selected. This closeness concept is calculated through the mathematical distance $L_{s, p}$ from the alternative $s$ to the ideal solution, depending on the metric $p$ (eq. 15). The lower value an alternative gets, the better it is.

$$
L_{s, p}=\left[\sum_{j=1}^{d} W_{j}^{p}\left[\sum_{i=1}^{m_{j}} W_{i j} \cdot \frac{F_{i}^{*}-f_{s i}}{F_{i}^{*}-f_{i}^{*}}\right]^{p}\right]^{1 / p}
$$

Where $d$ is again the number of dimensions; $f_{s i}$ is the value of the alternative $s$ for the criterion $i ; F_{i}^{*}$ is the ideal value for the criterion $i$ (the best among all alternatives); $f_{i}^{*}$ is the anti-ideal value for the criterion 
$i$ (the worst among all alternatives); and as known, $W_{i j}$ is the weight of the criterion $i$ belonging to dimension $j ; W_{j}$ is the weight of dimension $j$; and $m_{j}$ is the number of criteria attached to dimension $j$.

Finally, the metric $p$ represents the importance given to the deviation from the ideal value for each criterion and can vary from 1 to $\infty$ [56]. When increasing the $p$ value, a higher importance is assigned to the maximum deviation [56]. Thus, while $L_{s, 1}$ assignes the same importance to all deviations, $L_{s, \infty}$ considers only the maximum deviation of all criteria. Although different metrics can be applied, a linear combination of metrics 1 and $\infty$ is recommended in the literature and will therefore be used in this work (eq. 16) [57], with $\alpha=0.5$ :

$$
L_{s}=\alpha L_{s, 1}+(1-\alpha) L_{s, \infty}
$$

The best electrification design for a community corresponds to the lowest value of $L_{S}$.

\section{A CASE STUDY - ELECTRIFICATION OF RURAL COMMUNTIES IN PLATEAU STATE, NIGERIA}

Nigeria is the African country in which more people live without electricity access, at least 90 million [58]. $50 \%$ of Nigeria population cannot access electricity, while in rural areas this percentage raises up to $70 \%$ [59]. Small incentives for private investment due to electricity tariffs much below investment and operation costs [60] are highlighted as fundamental for such high non-electrification rates. Attempts for tariff regulation have faced strict opposition by consumers, since they are not usually included in the decisionmaking process [61] nor finally satisfied with the quality of supply provided. Indeed, the excessive unreliability of the national grid, due to lack of maintenance, vandalism and regular thefts [62], have forced to consider decentralized energy options based on MGs for electric supply.

In this context, between 2015 and 2017, a study integrated in the European-aid-funded project Nigerian Energy Support Program (NESP) analyzed the electricity demand of different population settlements of five Nigerian federal states using geospatial information and defined a multi-staged road map to provide electricity to each settlement [58,63]. For small settlements (with an overall peak demand lower than $50 \mathrm{~kW}$ ), solar home systems were chosen. Meanwhile, for big ones (villages to little towns) two electrification options were evaluated: a MG off-grid scenario based on solar PV, batteries and diesel generators; and the extension of the national grid without any backup. The electrification solution with lowest levelized cost of electricity (LCOE) for each big settlement was selected as final electrification design.

Now, the proposed multicriteria-based methodology is applied to 26 population settlements in order to include social, environmental and institutional aspects into a structured design and evaluation process. This integral process is considered a good opportunity to bridge the gap among institutions, private investors and end-consumers in Nigeria, and pretends to achieve higher consensus that benefit them all. 
The settlements (belonging to Plateau State, the state of Nigeria with lowest electrification rate of the ones analyzed in the NESP study) are selected so they can be representative of most rural communities in Nigeria. The selection focuses on two parameters: annual peak demand (indicative of the settlement's size) and distance to the closest national grid connection point. Figure 3 shows that the selected settlements are distributed all over Plateau State and cover peak demand values from 52 to $285 \mathrm{~kW}$. As it can be seen, all settlements present a peak demand higher than $50 \mathrm{~kW}$, which makes them suitable for decentralized energy systems based on MGs. In addition, different distances to the nearest national grid consumption point are taken into account, being the closest settlement $3 \mathrm{~km}$ and the furthest $65 \mathrm{~km}$ away from it. The two settlements numbered are taken as examples to later show the results obtained.

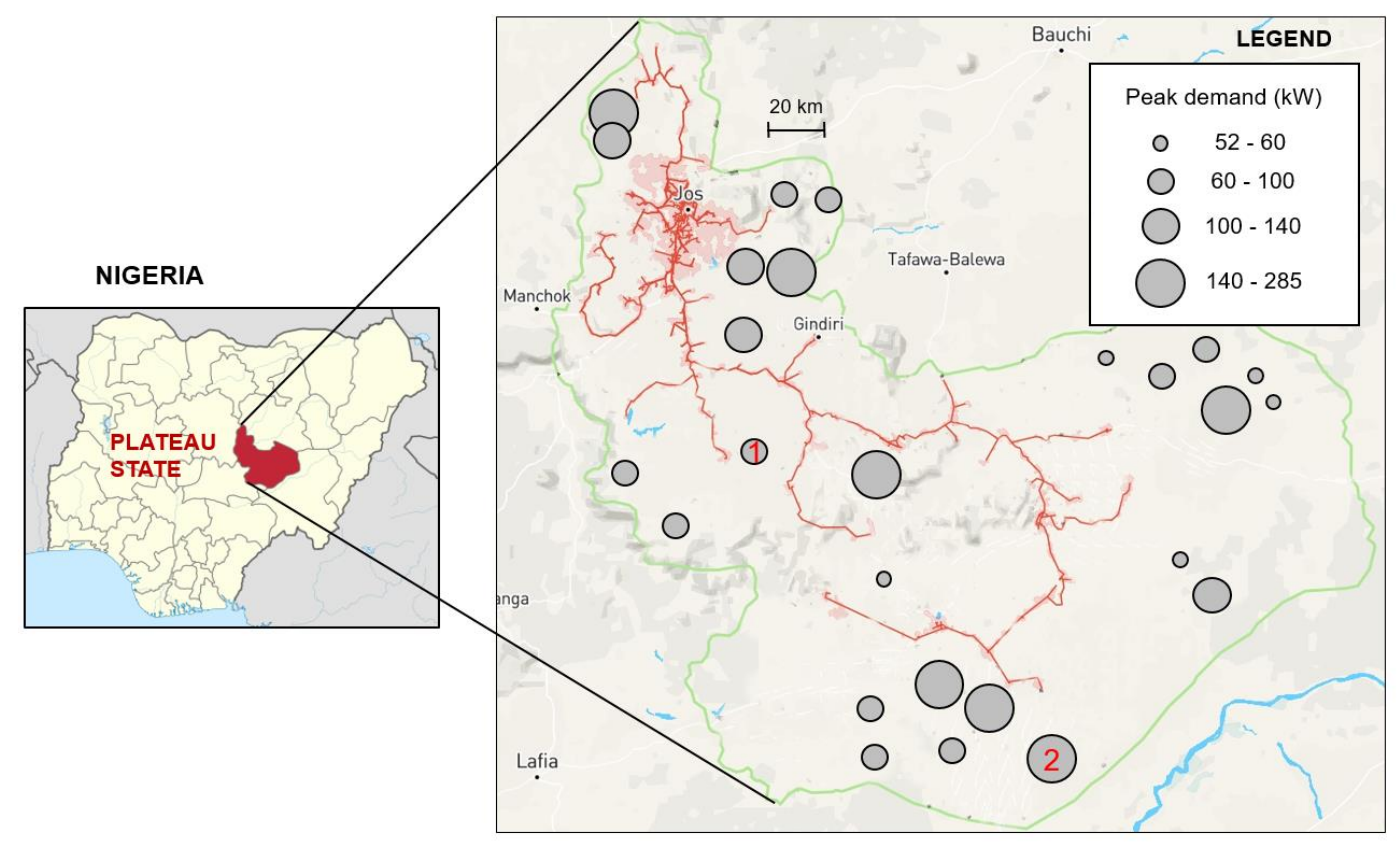

Figure 3. Selection of 26 settlements in Plateau State for the case study based on peak demand and distance to national grid (background image from http://rrep-nigeria.integration.org/\#)

The application of the design methodology aims to validate the procedure presented to design and select the best electrification alternative for each community taking into account the interests of public institutions, private investors and end-users through the presented multicriteria design process. In particular, for this case of Nigeria, the methodology is expected to mean a step forward towards a stronger collaboration between communities, private investors and public regulators which can help to reach agreements in the most appropriate design to fulfill quality expectations and allow more attractive returns of investment.

The rest of the section focus on displaying the main results of applying the design methodology shown in Figure 1. First (5.1), appropriate electrification scenarios for the case study are defined and the corresponding alternatives are obtained. Then (5.2), the results of the weighting of criteria and the 
technology assessment based on the questionnaires are presented. Next (5.3), results of previous steps are taken to evaluate and rank the alternatives considering all criteria. Finally (5.4), a definite electrification design for each community is recommended and a discussion of the results is realized.

\subsection{Scenarios definition and alternatives calculation}

For each settlement, different electrification scenarios are considered taking into account different technologies of electricity generation and system distributions. Photovoltaic solar energy has been widely used in Nigeria, due to its enormous solar potential, with fairly distributed solar radiation averaging 5.5 $\mathrm{kWhm}^{2} /$ day and average sunshine hours of 6h/day [64]. Meanwhile, wind energy systems have only had little applications in northern states, such as Sokoto and Katsina [65] and will therefore not be considered here. Moreover, the abovementioned unreliability of the national grid recommends considering always backup sources when the national grid is extended. Consequently, the following four electrification scenarios are analyzed for each community:

1. Off-grid system based on PV and batteries.

2. Off-grid system based on PV, batteries and diesel generators.

3. On-grid system based on PV and batteries.

4. On-grid system based on PV, batteries and diesel generators.

In addition, sub-scenarios are defined to determine the overall effect of considering shortages on the supply of annual demand. Particularly, three levels of shortage are considered for each electrification scenario: $0 \%$ (complete fulfillment of demand), $2.5 \%$ and $5 \%$. Therefore, 12 electrification alternatives are generated for each settlement (four electrification scenarios with three levels of shortage each).

Such alternatives are obtained using the optimization model detailed in section 3 , removing the components not included in each scenario. The data required is taken from the NESP study [63] and is summarized in Table 2. Additionally, two considerations must be given regarding the modelling of the national grid. On the one hand, the unreliability of the national grid can be modelled by a probability distribution of blackouts frequency (32.8 per month) and duration (11.6 hours on average), with a standard deviation of $15 \%$ [45]. These parameters allow to generate the binary data used in the electrification problem to indicate grid availability. On the other hand, the cost of grid extension was fixed in $20 \mathrm{~m} \$ / \mathrm{km}$ and is added to the total cost of on-grid alternatives as a post-process calculation, considering the distance to the closest national grid connection point. Any other economic or technical value not mentioned nor included in Table 2 is assumed to be non-conditioning: 0 , such as the operational expenditures for the consumption and feed-in transformer $\left(\right.$ opex $_{C}$, opex $\left._{F}\right)$ or 1 , such as the efficiencies of the inverter and the rectifier $\left(\eta_{I}, \eta_{R}\right)$.

Table 2. Economic and technical data

\begin{tabular}{|l|l|c|c|c|}
\hline \multicolumn{1}{|c|}{ Asset } & Parameter & Notation & Unit & Value \\
\hline PV & Investment costs & Inv & $\$ / \mathrm{kWp}$ & 1250 \\
\hline
\end{tabular}




\begin{tabular}{|c|c|c|c|c|}
\hline & Operational expenditures & opex $_{S}$ & $\$ / k W p / y$ & 25 \\
\hline & Lifetime & $t a_{S}$ & $\mathrm{y}$ & 25 \\
\hline \multirow{12}{*}{ Battery } & Power investment & \multirow{2}{*}{$\operatorname{Inv} v_{B}$} & $\$ / \mathrm{kW}$ & 500 \\
\hline & Capacity investment & & $\$ / \mathrm{kWh}$ & 250 \\
\hline & Variable cost & $\operatorname{Cvar}_{B}$ & $\$ / k W h$ & 6.75 \\
\hline & Maximum state of charge & SOCmax & factor & 1 \\
\hline & Minimum state of charge & SOCmin & factor & 0.2 \\
\hline & Inflow conversion factor & $\eta_{B i n}$ & factor & 0.97 \\
\hline & Outflow conversion factor & $\eta_{\text {Bout }}$ & factor & 0.97 \\
\hline & C-rate of charge & Cratein & factor & 1 \\
\hline & C-rate of discharge & Crateout & factor & 0.5 \\
\hline & Initial storage level & $P B_{0}$ & factor & 0 \\
\hline & Loss rate each timestep & $\varepsilon$ & factor & 0 \\
\hline & Lifetime & $t a_{B}$ & $y$ & 13.5 \\
\hline & Investment costs & $\operatorname{In} v_{D}$ & $\$ / \mathrm{kW}$ & 820 \\
\hline & Operational expenditures & Opex $_{D}$ & $\$ / \mathrm{kW} / \mathrm{a}$ & 0.05 \\
\hline Diesel & Efficiency & $\eta_{D}$ & factor & 0.33 \\
\hline & Lifetime & $t a_{D}$ & $\mathrm{y}$ & 10 \\
\hline & Diesel price & $p_{D}$ & $\$ / l$ & 1.04 \\
\hline & Investment costs & $\operatorname{In} v_{C}, \operatorname{In} v_{F}$ & $\$ / \mathrm{kW}$ & 200 \\
\hline Central arid & Lifetime & $t a_{C}, t a_{F}$ & $\mathrm{y}$ & 20 \\
\hline Venilial gira & Electricity consumption price & $p_{C}$ & $\$ / k W h$ & 0.08 \\
\hline & Electricity feed-in tariff & $p_{F}$ & $\$ / k W h$ & 0.05 \\
\hline & Discount factor & $d$ & $\%$ & 16 \\
\hline & Project lifetime & $t n$ & $\mathrm{y}$ & 20 \\
\hline Others & Optimization time horizon & $T$ & hours & 8760 \\
\hline & $\begin{array}{l}\text { Factor of demand supplied by } \\
\text { weather-independent sources }\end{array}$ & $S$ & factor & 0.2 \\
\hline
\end{tabular}

After the scenarios have been defined, phase 1 concludes with the generation of an electrification alternative for each scenario solving the optimization model detailed. This optimization process determines the optimal value of different items (Table 3), which are used in phase 2 to evaluate the alternatives. Since presenting the results for every settlement (26 in total) and every alternative (12 for each settlement) could be overwhelming, example results are displayed for two specific settlements and for some interesting alternatives: on-grid and off-grid scenarios, with only PV or also with diesel, and considering different shortage levels $(0 \%$ and $5 \%)$. Additionally, the range of values of every item considering all alternatives and settlements is also displayed. This range express a great difference as a result of the different size of the communities, the broad range of distances to the national grid and the different system designs considered.

Concerning the results for the example settlements, the investment costs are significantly reduced if different technologies of electricity generation are available. Also, on-grid scenarios tend to be more expensive than off-grid ones due to the cost of extending the national grid. Finally, optimal capacities and 
generation flows from the different assets are higher in the second settlement due to its higher size and demand.

Table 3. Optimization results of some electrification alternatives for two example settlements and the complete range of values

\begin{tabular}{|c|c|c|c|c|c|c|c|c|c|c|}
\hline \multirow{2}{*}{\multicolumn{2}{|c|}{ Optimization item }} & \multicolumn{4}{|c|}{ Example settlement 1} & \multicolumn{4}{|c|}{ Example settlement 2} & \multirow{2}{*}{$\begin{array}{l}\text { All settlements, } \\
\text { scenarios and } \\
\text { sub-scenarios } \\
\text { (if not zero) }\end{array}$} \\
\hline & & $\begin{array}{c}\text { On-grid } \\
\text { PV } \\
0 \%\end{array}$ & $\begin{array}{c}\text { On-grid PV } \\
\text { \& diesel } \\
0 \% \\
\end{array}$ & $\begin{array}{c}\text { Off-grid } \\
\text { PV } \\
5 \%\end{array}$ & $\begin{array}{c}\text { Off-grid PV } \\
\text { \& diesel } \\
5 \% \\
\end{array}$ & $\begin{array}{c}\text { On-grid } \\
\text { PV } \\
0 \%\end{array}$ & $\begin{array}{c}\text { On-grid PV } \\
\& \text { diesel } \\
0 \%\end{array}$ & $\begin{array}{c}\text { Off-grid } \\
\text { PV } \\
5 \%\end{array}$ & $\begin{array}{c}\text { Off-grid PV } \\
\text { \& diesel } \\
5 \% \\
\end{array}$ & \\
\hline Investment costs & $\mathrm{m} \$$ & 787.35 & 355.82 & 653.03 & 249.81 & 2073.55 & 1194.85 & 1420.06 & 628.39 & $169-7365$ \\
\hline O\&M balance & $\mathrm{m} \$ / \mathrm{y}$ & 44.23 & 65.96 & 452.84 & 82.29 & 126.49 & 173.00 & 131.90 & 208.54 & $31-720$ \\
\hline $\begin{array}{l}\text { Annual PV } \\
\text { generation }\end{array}$ & $\mathrm{kWh}$ & 214800 & 72231 & 259122 & 90208 & 524177 & 152589 & 511534 & 185751 & $31679-3575925$ \\
\hline $\begin{array}{l}\text { Annual diesel } \\
\text { generation }\end{array}$ & $\mathrm{kWh}$ & 0 & 47574 & 0 & 114567 & 0 & 91605 & 0 & 237278 & $23189-1021049$ \\
\hline $\begin{array}{l}\text { Annual grid } \\
\text { consumption }\end{array}$ & kWh & 14960 & 85471 & 0 & 0 & 10902 & 183757 & 0 & 0 & $940-769352$ \\
\hline Capacity PV & $\mathrm{kWp}$ & 144.00 & 48.42 & 173.72 & 60.48 & 331.12 & 96.39 & 323.13 & 117.34 & $21-2253$ \\
\hline Capacity diesel & $\mathrm{kW}$ & 0 & 47.61 & 0 & 32.70 & 0 & 113.54 & 0 & 81.30 & $17-564$ \\
\hline $\begin{array}{l}\text { Capacity grid } \\
\text { transformer }\end{array}$ & $\mathrm{kW}$ & 25.56 & 44.31 & 0 & 0 & 95.53 & 110.94 & 0 & 0 & $11-492$ \\
\hline Capacity battery & kW & 519.53 & 46.40 & 411.05 & 26.40 & 1052.16 & 143.53 & 901.51 & 100.07 & $11-5558$ \\
\hline
\end{tabular}

\subsection{Criteria weights and technology assessment results}

Phase 2 of the design methodology requires to particularize the evaluation and ranking procedure according to the Nigerian context. Therefore, questionnaires (Appendixes A and B) were handed out to 10 experts in rural electrification in Nigeria. All experts count on more than 6 years of experience in different areas (public administration, Nigeria government, private companies and non-governmental organizations) and are therefore representative of all stakeholders involved in the electricity market. The survey consists of two sections: section 1 asked for an evaluation of the importance of the 12 criteria on a scale from 1 to 5 (very low importance to very high importance). Then, section 2 asked to punctuate the performance on the qualitative criteria of the three technologies of electricity generation considered in the case study (solar PV, diesel, and national grid extension) on a scale from 1 to 3 (low performance to good performance). These punctuations are included in the indicators to evaluate the qualitative criteria as explained in section 4.3 and detailed in Table 1. The aggregated results of the surveys are displayed in Tables 4 and 5. In the following paragraphs, the main findings are presented as well as their justification through comments from the respondent experts on the surveys.

The highest weight is assigned to the economic dimension due to the importance of its two criteria: while investment costs (EC-1) are key to raise funding (experts 1, 4 and 5), O\&M costs (EC-2) directly affect the long-term sustainability of the project (expert 2). Regarding the technical dimension, all experts agree to highlight the need of a reliable and resistant supply. Consequently, and considering the unreliability of the national grid, a high autonomy factor $(\mathrm{T}-1)$ is also prioritized. Oppositely, the lowest weight among the technical criteria is assigned to T-2, as a small shortage on demand supplied is acceptable (experts 
1 and 2). Concerning the socio-institutional dimension, an affordable tariff for electrical service (S-1) directly impact the business model sustainability (expert 4), while aligning the electrification solution with institutional goals (S-3) allows higher chances to gain subsidies (expert 5). Finally, the lowest weight of EN-1 within the environmental dimension is explained by a prioritization of supplying electricity, no matter the source (expert 1) and due to the low economic incentives given by the Nigeria government to clean electricity generation (expert 5). Contrarily, although most waste is currently being disposed informally (expert 10), Renewable Energy Recycling Policy is an emerging issue that aims at increasing awareness of the wastes generation (expert 6).

Table 4. Weights for dimensions and criteria

\begin{tabular}{|c|c|c|c|c|}
\hline Dimensions & Weights & & Criteria & Weights \\
\hline \multirow{2}{*}{ Economic } & \multirow{2}{*}{0.286} & EC-1 & Initial investment & 0.514 \\
\hline & & EC-2 & O\&M costs & 0.486 \\
\hline \multirow{4}{*}{ Technical } & \multirow{4}{*}{0.258} & $\mathrm{~T}-1$ & Autonomy factor & 0.260 \\
\hline & & $\mathrm{T}-2$ & Complete fulfilment of demand & 0.238 \\
\hline & & T-3 & Reliability of generation sources & 0.247 \\
\hline & & T-4 & Equipment failure & 0.255 \\
\hline \multirow{3}{*}{$\begin{array}{l}\text { Socio- } \\
\text { institutional }\end{array}$} & \multirow{3}{*}{0.234} & S-1 & Tariff for electrical service & 0.396 \\
\hline & & S-2 & Users acceptance & 0.265 \\
\hline & & S-3 & Institutional alignment & 0.338 \\
\hline \multirow{3}{*}{ Environmental } & \multirow{3}{*}{0.222} & $\mathrm{EN}-1$ & $\mathrm{CO}_{2}$ emissions & 0.256 \\
\hline & & $\mathrm{EN}-2$ & E-Impact on population & 0.384 \\
\hline & & EN-3 & Wastes of components & 0.360 \\
\hline
\end{tabular}

With respect to the technology assessment in section 2, all experts agree on the unreliability of the national grid due to constant failures. Oppositely, solar PV overcomes diesel in reliability of supply due to the number of sun hours in Nigeria (expert 6), the reduced number of moving parts that might cause failure (expert 10), and the better performance if good-quality components are used (expert 4). However, the existing higher diesel diffusion rate compared to solar PV (experts 2 and 6) makes diesel systems more desirable to users, who still show low awareness of solar PV technology (experts 7 and 8). Moreover, solar PV is the government's priority to electrify rural areas (experts 4 and 5), although the national grid is also greatly considered. Finally, low punctuations of solar PV and diesel in wastes generation are caused by high wastes at the end of lifetime (majorly due to batteries) and continuous gas emissions, respectively (expert 5).

Table 5. Punctuations to qualitative criteria

\begin{tabular}{|l|c|c|c|}
\hline Criteria & Solar PV & Diesel & National grid \\
\hline Reliability of generation sources & 2.75 & 1.88 & 1.13 \\
\hline Equipment failure & 2.25 & 1.50 & 1.13 \\
\hline Users acceptance & 2.00 & 2.67 & 2.17 \\
\hline Institutional alignment & 2.57 & 1.71 & 2.14 \\
\hline E-Impact on population & 2.63 & 1.00 & 1.88 \\
\hline Wastes of components & 1.63 & 1.50 & 2.63 \\
\hline
\end{tabular}




\subsection{Alternatives evaluation and ranking}

Once the electrification alternatives are generated and the evaluation procedure is particularized, the different alternatives are evaluated according to each criterion and dimension, and a ranking for each settlement is obtained. Once more, only the results of the evaluation of four alternatives for two example settlements are displayed (Table 6). Relevant information is now given to allow a better understanding of the evaluation procedure and its connection to previous results.

As defined in Table 1, the evaluation for the economic criteria (EC-1 and EC-2) correspond exactly to the investment costs and the O\&M balance achieved in Table 3. Also, the autonomy factor (T-1) is only $100 \%$ for off-grid configurations, and the shortage level allowed in each sub-scenario determines the fulfillment of demand (T-2). Regarding the qualitative criteria, the results of the assessment of the PV technology directly set the evaluation of the off-grid alternatives which consider only PV, as this is the only technology included. Their evaluation for other alternatives result on a weighted average ratio of electricity generation (for T-3, T-4, S-2, S-3) and power capacity (for EN-2, EN-3) from the different technologies (weighted by the punctuations in Table 5).

Finally, compromise ranking method is used to rank the alternatives for each settlement. As said, the lower the distance to the ideal solution is $\left(L_{s}\right)$, the better the alternative. Therefore, for these settlements the best electrification alternatives are an on-grid and an off-grid configuration, respectively, using only $\mathrm{PV}$ technology within the MG.

Table 6. Evaluation results of some electrification alternatives for two example settlements

\begin{tabular}{|c|c|c|c|c|c|c|c|c|c|c|}
\hline \multirow[b]{2}{*}{ Dimensions } & & & \multicolumn{4}{|c|}{ Example settlement 1} & \multicolumn{4}{|c|}{ Example settlement 2} \\
\hline & \multicolumn{2}{|c|}{ Criteria } & $\begin{array}{l}\text { On-grid } \\
\text { PV } \\
0 \%\end{array}$ & $\begin{array}{c}\text { On-grid PV } \\
\& \text { diesel } \\
0 \%\end{array}$ & $\begin{array}{c}\text { Off-grid } \\
\text { PV } \\
5 \% \\
\end{array}$ & $\begin{array}{c}\text { Off-grid PV } \\
\& \text { diesel } \\
5 \%\end{array}$ & $\begin{array}{c}\text { On-grid } \\
\text { PV } \\
0 \% \\
\end{array}$ & $\begin{array}{c}\text { On-grid PV } \\
\& \text { diesel } \\
0 \%\end{array}$ & $\begin{array}{c}\text { Off-grid } \\
\text { PV } \\
5 \% \\
\end{array}$ & $\begin{array}{c}\text { Off-grid PV } \\
\& \text { diesel } \\
5 \%\end{array}$ \\
\hline \multirow{2}{*}{ Economic } & EC-1 & $\mathrm{m} \$$ & 787.35 & 355.82 & 653.03 & 249.81 & 2073.55 & 1194.85 & 1420.06 & 628.39 \\
\hline & EC-2 & $\mathrm{m} \$ / \mathrm{y}$ & 44.23 & 65.96 & 452.84 & 82.29 & 126.49 & 173.00 & 131.90 & 208.54 \\
\hline \multirow{4}{*}{ Technical } & $\mathrm{T}-1$ & $\%$ & 92.65 & 58.03 & 100 & 100 & 97.43 & 56.74 & 100 & 100 \\
\hline & $\mathrm{T}-2$ & $\%$ & 100 & 100 & 95 & 95 & 100 & 100 & 95 & 95 \\
\hline & $\mathrm{T}-3$ & factor & 2.77 & 2.65 & 2.75 & 2.26 & 2.76 & 2.67 & 2.75 & 2.26 \\
\hline & $\mathrm{T}-4$ & factor & 2.30 & 2.39 & 2.25 & 1.83 & 2.26 & 2.41 & 2.25 & 1.83 \\
\hline \multirow{3}{*}{$\begin{array}{l}\text { Socio- } \\
\text { institutional }\end{array}$} & S-1 1 & $\begin{array}{c}\$ / \\
\mathrm{kWh}\end{array}$ & 0.46 & 0.46 & 0.67 & 0.67 & 0.46 & 0.46 & 0.67 & 0.67 \\
\hline & S-2 & factor & 2.01 & 2.21 & 2.00 & 2.34 & 2.00 & 2.20 & 2.00 & 2.33 \\
\hline & $\mathrm{S}-3$ & factor & 2.54 & 2.19 & 2.57 & 2.09 & 2.56 & 2.20 & 2.57 & 2.09 \\
\hline \multirow{3}{*}{ Environmental } & $\mathrm{EN}-1^{2}$ & tons & 6.58 & 74.24 & 0 & 182.24 & 4.80 & 151.39 & 0 & 182.70 \\
\hline & EN-2 & factor & 2.52 & 1.84 & 2.63 & 2.06 & 2.46 & 1.79 & 2.63 & 1.96 \\
\hline & EN-3 & factor & 1.67 & 1.83 & 1.63 & 1.60 & 1.69 & 1.84 & 1.63 & 1.59 \\
\hline & & $L_{s, 1}$ & 0.405 & 0.534 & 0.398 & 0.644 & 0.431 & 0.574 & 0.397 & 0.670 \\
\hline & & $L_{S, \infty}$ & 0.126 & 0.193 & 0.155 & 0.197 & 0.154 & 0.192 & 0.155 & 0.203 \\
\hline
\end{tabular}

\footnotetext{
${ }^{1}$ The tariff for electrical service in Nigeria is set to $0.67 \$ / \mathrm{kWh}$ for off-grid scenarios and $0.46 \$ / \mathrm{kWh}$ for on-grid ones, based on a World Bank report [66] and calculations realized following the Multi-Year Tariff Order (MYTO) methodology (compulsory for tariff calculation of mini-grids in Nigeria and controlled by the Nigerian Electricity Regulatory Comission, NERC).

2 The emission factor for the Nigerian national grid is set to $0.44 \mathrm{~kg} \mathrm{CO} / \mathrm{kWh}$ [67]
} 


\begin{tabular}{|l|l|l|l|l|l|l|l|l|}
\hline$L_{S}$ & $\mathbf{0 . 2 6 6}$ & 0.364 & 0.277 & 0.421 & 0.293 & 0.383 & $\mathbf{0 . 2 7 6}$ & 0.437 \\
\hline
\end{tabular}

\subsection{Final electrification design for each community}

After completing the evaluation and ranking processes for each of the 26 settlements, a final system design can be recommended for each one. Thus, Figure 4 presents the best electrification alternative for each settlement. Analyzing the results, both on-grid and off-grid configurations stand out as viable and its selection depends on the communities' features. However, a total predominance of solar PV technology in respect to diesel is shown. Although including diesel generators in the electrification scenario can drastically reduce investment costs ( $52.3 \%$ on average with a standard deviation of $10.7 \%$ ), the influence of all criteria together balance this out in favor of solar PV. Next paragraphs aim to explain the reasons behind the results of the grid configuration and the shortage level, which need further analysis.

Basically, an on-grid or an off-grid configuration for a specific settlement depends on the peak demand of the community and its distance to the national grid (Figure 5). It is shown that the greater the peak demand is, the more attractive a settlement gets for on-grid alternatives. Thus, off-grid and on-grid alternatives can excel to be the best option for communities with similar distance to the national grid depending on their size. The boundaries between the two zones shown in Figure 5 determinate the size of a settlement needed to compensate the cost of grid extension for each specific distance.

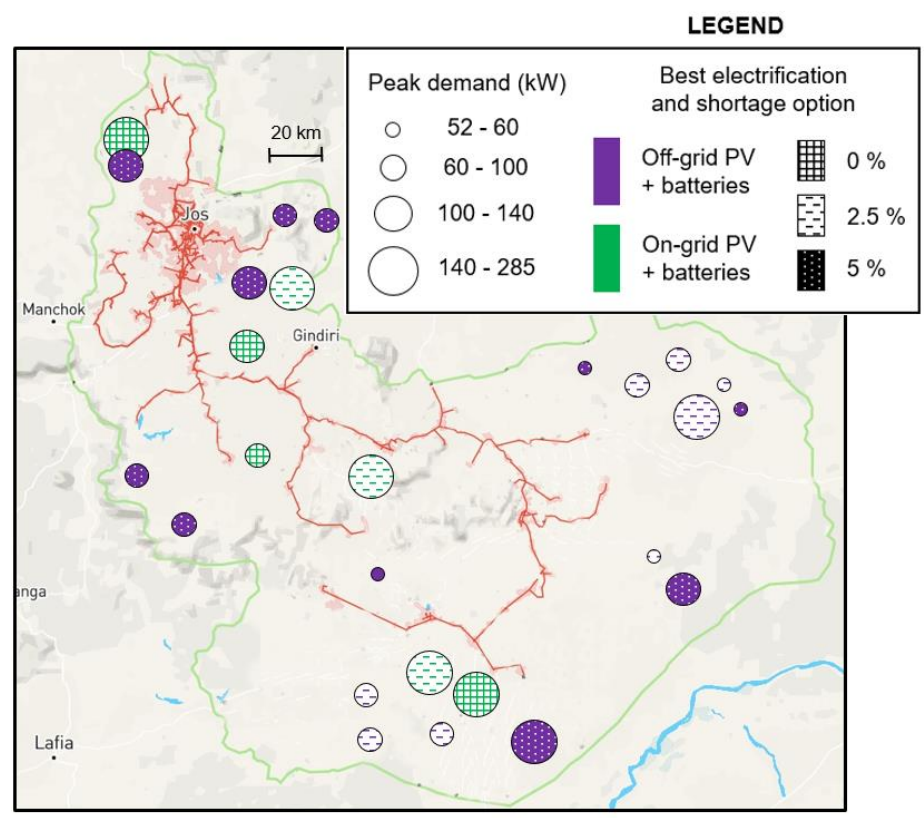

Figure 4. Final electrification alternative selected for each settlement (background image from http://rrep-

nigeria.integration.org/\#)

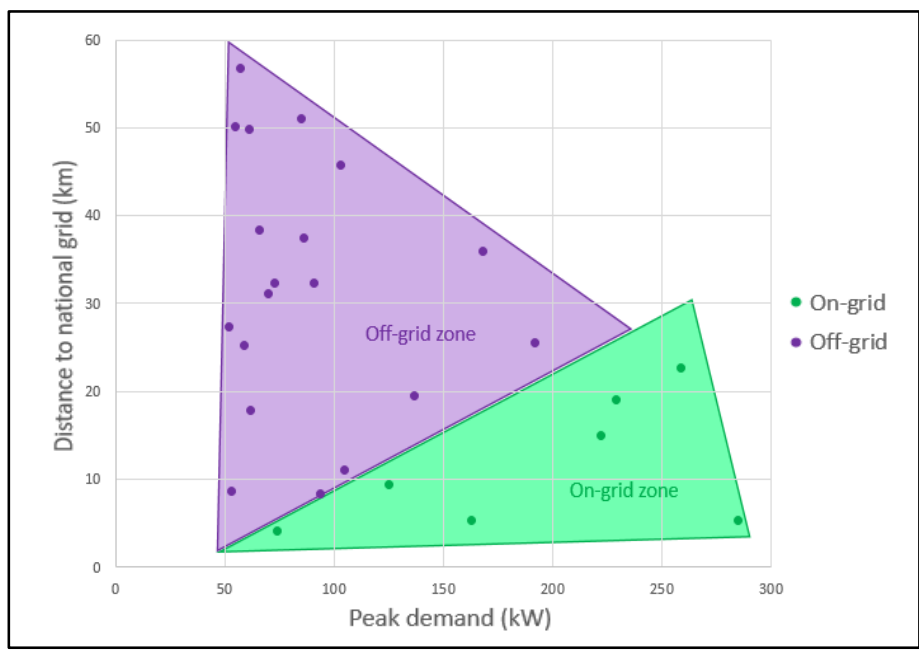

Figure 5. Division of settlements into zones according to the predominance of each configuration 
In the scenarios definition step, sub-scenarios were also defined to calculate electrification alternatives for three levels of shortage on annual demand (0\%, for complete fulfillment of demand; $2.5 \%$; and $5 \%$ ). Table 7 classifies each settlement (26 in total) regarding the best system configuration and the best shortage level obtained. As a first conclusion, as expected, the higher the shortage level, the lower percentage of annual demand supplied, so the lower the investment costs of the electrification system. With that in mind, the results of the analysis (Table 7) show that higher levels of shortage are the best option for off-grid configurations, due to the higher weight given to the investment costs (EC-1) criterion in comparison with the fulfillment of demand (T-2) (Table 3). Contrarily, low levels of shortage are better when on-grid configurations are recommended. Due to the unreliability of the Nigerian national grid, a high fulfillment of demand ( $0 \%$ and $2.5 \%$ shortage) must be achieved with a higher share of solar PV compared with national grid consumption; which is beneficial throughout the multicriteria evaluation as the solar PV technology has been better punctuated in most qualitative criteria.

Table 7. Best shortage levels for each system configuration

\begin{tabular}{|l|l|c|c|c|}
\hline \multicolumn{2}{|l|}{$\begin{array}{l}\text { Number of settlements in } \\
\text { each combination }\end{array}$} & \multicolumn{3}{|c|}{ Shortage levels } \\
\cline { 2 - 5 } & $0 \%$ & $2.5 \%$ & $5 \%$ \\
\hline \multirow{2}{*}{$\begin{array}{l}\text { System } \\
\text { configuration }\end{array}$} & On-grid & 4 & 3 & 0 \\
\cline { 2 - 5 } & Off-grid & 0 & 8 & 11 \\
\hline
\end{tabular}

Finally, the whole results shown are compared with the least-cost electricity option recommended in the NESP study [63]. Regarding the systems configuration, there is a significant increase in off-grid recommendations when including a multicriteria approach. In detail, only $40 \%$ of on-grid configurations in the NESP study remain unchanged in this study, while an off-grid configuration is now the best option for the other $60 \%$. Oppositely, $100 \%$ of off-grid configurations in the NESP study continue to be the best electrification option also in this study. Regarding the technologies of electricity generation, a better or equal performance of solar PV compared to diesel in 10 out of 12 criteria compensates the increase of upfront investment costs and supports the recommendation to promote systems based on PV and batteries for MGs in Nigeria. This comparison should reinforce decision-makers to consider multiple criteria to design more appropriate electrification systems for rural areas.

Overall, these results encourage continuous institutional efforts on improving both public and private capacities to face electrification programs that go beyond traditional grid extension, centralized electricity generation sources and only cost-orientated designs. Indeed, the Nigerian Rural Electrification Agency (REA), in collaboration with the World Bank, has recently started an ambitious electrification project to increase electricity access throughout the country, giving priority to solar-based MGs and considering social and technical aspects in the design [68]. In this line, two final conclusions that should orientate the focus of policy makers in Nigeria in the near future are the following:

- Off-grid electrification of mainly small and medium-sized communities through microgrids stand out as an appropriate solution from a certain distance to the main grid (as seen in Figure 5). 
Further regulation should be implemented to provide a safe and attractive environment for private investors to promote systems of this kind.

- The highlighted benefits of solar PV technology compared to diesel, as well as its recent tendency of market cost reduction [69], envisages a most predominance use of solar PV in the near future, which should continue to be promoted from the institutional side.

\section{CONCLUSIONS}

This work develops a multicriteria procedure to evaluate rural electrification systems considering on-grid or off-grid MGs and different technologies of electricity generation (solar PV, wind or diesel). This procedure is integrated in a two-phased methodology to first generate electrification designs and then select the most appropriate one for each community according to the multicriteria procedure. In phase 1 , alternatives are generated through techno-economic optimizations. The optimization model used is extended from previous studies with additional assets and constraints to allow the generation of more complete and reliable electrification designs. To evaluate and rank these alternative designs in phase 2 , 12 criteria are selected and defined. The criteria evaluation through indicators is based on the outputs of the optimization model. Thus, a perfect integration of alternatives generation and selection phases can be achieved. Consequently, decision-makers dispose of an integrated tool to determine different electrification designs and select the most appropriate guided by a comprehensive final ranking.

The 12 criteria are grouped into four dimensions: economical, technical, socio-institutional and environmental. First, economic criteria include upfront investment costs and operation and maintenance expenditures needed during the projects' lifetime. Second, technical criteria consider the autonomy factor of the system, the existence of small shortages on demand, the reliability of supply against forecasts and the likelihood of equipment failure. Third, the socio-institutional dimension takes into account the tariff for electrical service, the users' acceptance of the different technologies of electricity generation and the alignment of these technologies with the government's tendency. Finally, environmental criteria include $\mathrm{CO}_{2}$ emissions, environmental impact of the project based on visual, noise impact and land-use, and wastes generation.

The whole design methodology is applied in a case study of 26 different population settlements in Plateau State, Nigeria, which present different values of peak demand and distances to the closest national grid consumption point. Questionnaires to experts in Nigeria electrification context are assessed to determinate the weights of the criteria and to evaluate the performance of the different technologies of electricity generation (solar PV, diesel and the national grid extension) for each qualitative criterion. Four main electrification scenarios are considered for each community combining MG off-grid and on-grid configurations with only solar PV and batteries, or including also diesel generators. Results are provided for the main steps of the methodology: alternatives calculation, criteria weighing and alternatives evaluation and ranking. The design procedure concludes with a final recommendation design for each community: on the one hand, an on-grid alternative based on solar PV and batteries is recommended for 
7 settlements, with a distance to the national grid no bigger than $25 \mathrm{~km}$. On the other hand, an off-grid solution based on solar PV and batteries is recommended for 19 settlements, for which an insufficient peak demand does not compensate the cost of extending the national grid. Finally, sub-scenarios defined considering different shortage levels on annual demand supplied show that a small shortage (2.5 - 5\%) is attractive for off-grid scenarios, in order to reduce investment costs. Ultimately, the results obtained remark the adequacy of off-grid microgrids based on solar PV and batteries to electrify rural areas, which should be promoted and carefully regulated by the institutions involved.

Future lines of research must focus on extend the defined static design procedure into a dynamic methodology capable of dividing the electrification of rural communities into progressive steps along time. This is an even more attractive approach for electrification planning as decisions are taken considering all communities at once and feasible objectives can be set for concrete periods of time.

\section{ACKNOWLEGMENTS}

This research was funded by the Spanish Ministry of Science, Innovation and Universities (pre-doctoral scholarship FPU18/05389 and research project RTI2018-097962-B-I00), and cofunded by the Centre of Cooperation for Development (CCD) of the Universitat Politècnica de Catalunya - BarcelonaTech (UPC). The work has been possible thanks to the financial support received also from the InnoEnergy PhD School program (2019) and the essential collaboration of all energy experts consulted belonging to the Reiner Lemoine Institut, Zahra Energy, CREEDS Energy LTD, German Corporation for International Cooperation (GIZ)-Nigeria, Rural Electrification Agency (REA)-Nigeria, Wuppertal Institute for Climate, Environment and Energy and the NGOs PowerForAll, Clean Technology Hub and Nature Care Resource Center.

\section{APPENDIX A}

To weight the criteria and dimensions for the presented case study using equation (eq. 14), first different experts must give an importance rating to the 12 criteria on a scale from 1 (very low importance) to 5 (very high importance). Their results for the case study are presented in Table 4.

\begin{tabular}{|c|c|c|c|c|c|}
\hline \multicolumn{6}{|c|}{ Importance ranking scale } \\
\hline 1 & 2 & 3 & 4 & 5 & Z \\
\hline $\begin{array}{l}\text { Very low } \\
\text { importance }\end{array}$ & Low importance & $\begin{array}{c}\text { Moderate } \\
\text { importance }\end{array}$ & High importance & $\begin{array}{l}\text { Very high } \\
\text { importance }\end{array}$ & Don't know \\
\hline
\end{tabular}

\begin{tabular}{|l|l|l|l|}
\hline \multicolumn{2}{|l|}{ ECONOMIC DIMENSION } & Indicator & Importance \\
\hline Criteria & Short description & Sum of all investments costs (\$). \\
\hline $\begin{array}{l}\text { Initial } \\
\text { investment } \\
\text { costs }\end{array}$ & $\begin{array}{l}\text { Capital costs needed to be invested in the first } \\
\text { moment, to set up the project. }\end{array}$ & $\begin{array}{l}\text { Sum of all costs related to operation and maintenance of } \\
\text { equipment and fuel and grid consumption expenditures (\$). }\end{array}$ & $\begin{array}{l}\text { Costs paid during the project lifetime to operate } \\
\text { and maintain the electrical equipment. It also } \\
\text { includes other expenditures such as fuel supply } \\
\text { and grid consumption costs. }\end{array}$ \\
$\begin{array}{l}\text { Operation, } \\
\text { maintenance } \\
\text { costs }\end{array}$
\end{tabular}

TECHNICAL DIMENSION 


\begin{tabular}{|c|c|c|}
\hline $\begin{array}{l}\text { Autonomy } \\
\text { factor }\end{array}$ & $\begin{array}{l}\text { System degree of autonomy stating how much } \\
\text { electricity is produced within the mini-grid and how } \\
\text { much is consumed from national grid. }\end{array}$ & $\begin{array}{l}\text { Percentage of electricity generated locally within the mini- } \\
\text { grid (due to renewable sources or diesel generators) vs all } \\
\text { electricity generated (\%) }\end{array}$ \\
\hline $\begin{array}{l}\text { Complete } \\
\text { fulfilment of } \\
\text { demand }\end{array}$ & $\begin{array}{l}\text { Importance of completely fulfil demand, as little } \\
\text { shortages on annual supply compared to annual } \\
\text { demand (around } 2-5 \% \text { ) could significantly reduce } \\
\text { investment costs }(5-15 \%) \text {. }\end{array}$ & $\begin{array}{l}\text { Percentage of annual electricity supplied vs annual demand } \\
(\%) .\end{array}$ \\
\hline $\begin{array}{l}\text { Reliability of } \\
\text { generation } \\
\text { sources }\end{array}$ & $\begin{array}{l}\text { Robustness of the generation sources, as weather } \\
\text { variability could slightly modify solar forecasts, } \\
\text { while deficient infrastructures can provoke delays } \\
\text { in fuel supply. }\end{array}$ & $\begin{array}{l}\text { Weighted sum of the electricity generated by each } \\
\text { generation source, weighted by qualitative punctuations } \\
\text { according to their reliability (section } 2 \text { of this questionnaire) } \\
\text { (factor). }\end{array}$ \\
\hline $\begin{array}{l}\text { Equipment } \\
\text { failure }\end{array}$ & $\begin{array}{l}\text { Likelihood of equipment failure due to technical or } \\
\text { mechanical issues, lack of maintenance or } \\
\text { extreme meteorological phenomena (high } \\
\text { temperatures, strong wind or high precipitations) }\end{array}$ & $\begin{array}{l}\text { Weighted sum of the electricity generated by each } \\
\text { generation source, weighted by qualitative punctuations } \\
\text { according to the likelihood of equipment failure for each } \\
\text { generation source (section } 2 \text { of this questionnaire) (factor). }\end{array}$ \\
\hline
\end{tabular}

\begin{tabular}{|c|c|c|c|}
\hline \multicolumn{4}{|c|}{ SOCIO-INSITUTIONAL DIMENSION } \\
\hline Criteria & Short description & Indicator & Importance \\
\hline $\begin{array}{l}\text { Tariff for } \\
\text { electrical } \\
\text { service }\end{array}$ & $\begin{array}{l}\text { Amount of money to be payed by the end-user } \\
\text { each month for the electrical service. }\end{array}$ & $\begin{array}{l}\text { Mean amount of money an habitant of a community must } \\
\text { pay monthly, based on Jos DisCo electrical tariff and NERC } \\
\text { regulation for mini-grids ( } \$ / \mathrm{kWh}) \text {. }\end{array}$ & \\
\hline $\begin{array}{l}\text { Users } \\
\text { acceptance }\end{array}$ & $\begin{array}{l}\text { Acceptability of the different generation sources. } \\
\text { The sociocultural context of the community and } \\
\text { previous experience can affect their approval by } \\
\text { the consumers. }\end{array}$ & $\begin{array}{l}\text { Weighted sum of the electricity generated by each } \\
\text { generation source, weighted by qualitative punctuations } \\
\text { according to the users acceptance of each of them (section } \\
2 \text { of this questionnaire) (factor). }\end{array}$ & \\
\hline $\begin{array}{l}\text { Institutional } \\
\text { alignment }\end{array}$ & $\begin{array}{l}\text { Alignment of the generation sources with the } \\
\text { national trend of Nigeria government. }\end{array}$ & $\begin{array}{l}\text { Weighted sum of the electricity generated by each } \\
\text { generation source, weighted by qualitative punctuations } \\
\text { according to their alignment with Nigeria government's } \\
\text { national trend (section } 2 \text { of this questionnaire) (factor). }\end{array}$ & \\
\hline
\end{tabular}

\begin{tabular}{|l|l|l|l|}
\hline \multicolumn{2}{|l|}{ ENVIRONMENTAL DIMENSION } & Indicator & Importance \\
\hline Criteria & Short description & $\begin{array}{l}\text { Tones of } \mathrm{CO}_{2} \text { emitted due to the diesel generators or the } \\
\text { electrical national grid (tones } \mathrm{CO}_{2} \text { ). }\end{array}$ & $\begin{array}{l}\text { Weighted sum of the optimized power capacity of each } \\
\text { generation source, weighted by qualitative punctuations } \\
\text { according to their impact on population (section } 2 \text { of this } \\
\text { questionnaire) (factor). }\end{array}$ \\
\hline $\begin{array}{l}\text { Impact on } \\
\text { population }\end{array}$ & $\begin{array}{l}\text { Negative affections on local population due to } \\
\text { visual impact, noise and land-use as a result of the } \\
\text { installation and operation of the electrical } \\
\text { equipment. }\end{array}$ & $\begin{array}{l}\text { Wastes generation at the end of the components } \\
\text { lifetime, including which percentage of them allow } \\
\text { recycle or reuse and how easy each } \\
\text { decommission is. This issue is particularly tricky } \\
\text { for batteries. }\end{array}$ & $\begin{array}{l}\text { Weighted sum of the optimized power capacity of each } \\
\text { according to wastes generation of each component (section } \\
\text { 2 of this questionnaire) (factor). }\end{array}$ \\
\hline $\begin{array}{l}\text { Wastes of } \\
\text { components }\end{array}$ & & \\
\hline
\end{tabular}

\section{APPENDIX B}

To evaluate the qualitative criteria according to the indicators definition in Table 1, first different experts must punctuate the performance of each technology for electricity generation included in the case study (PV, diesel and the national grid) regarding each qualitative criterion on a scale from 1 (weak performance) to 3 (good performance). The results of the questionnaire for the case study are presented in Table 5.

\begin{tabular}{|c|c|c|c|}
\hline \multicolumn{4}{|c|}{ Performance evaluation } \\
\hline 1 & 2 & 3 & $Z$ \\
\hline $\begin{array}{c}\text { Weak } \\
\text { performance }\end{array}$ & $\begin{array}{c}\text { Medium } \\
\text { performance }\end{array}$ & $\begin{array}{c}\text { Good } \\
\text { performance }\end{array}$ & Don't know \\
\hline
\end{tabular}

\begin{tabular}{|l|l|l|l|}
\hline QUALITATIVE CRITERIA & PV plant & Diesel generators & National grid \\
\hline
\end{tabular}




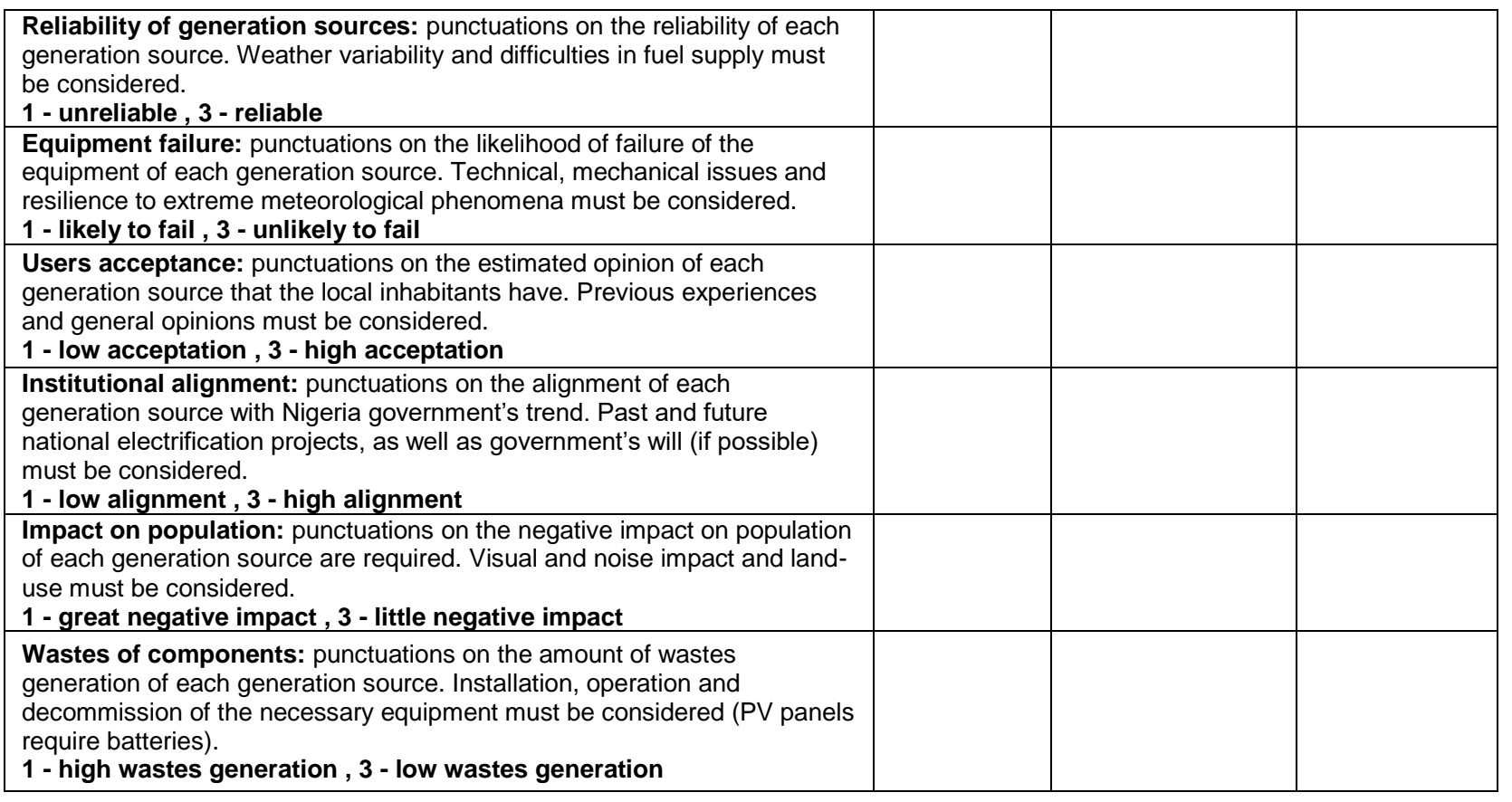

\section{REFERENCES}

[1] IEA, International Energy Association. World energy outlook (2019)

[2] Domenech B, Ranaboldo M, Ferrer-Martí L, Pastor R, Flynn D. Local and regional microgrid models to optimise the design of isolated electrification projects. Renewable Energy 119 (2018) 795-808

[3] Ferrer-Martí L, Garwood A, Chiroque J, Ramirez B, Marcelo O, Garfí M, Velo E. Evaluating and comparing three community small-scale wind electrification projects, Renewable \& Sustainable Energy Reviews 16 (2012) 53795390

[4] Ferrer-Martí L, Pastor R, Capó G.M, Velo E. Optimizing microwind rural electrification projects. A case study in Peru. Journal of Global Optimization 50 (2011), 127-143

[5] Ustun T.S, Ozansoy C, Zayegh A. Recent developments in microgrids and example cases around the worldA review. Renewable and Sustainable Energy Reviews 15 (2011) 4030-4041

[6] Blechinger, P., Köhler, M., Juette, C., Berendes, S. and Nettersheim, C. Off-Grid Renewable Energy for Climate Action - Pathways for change, Deutsche Gesellschaft für Internationale Zusammenarbeit (GIZ), (2019a)

[7] Hatziargyriou N, Asano H, Iravani R, Marnay C. Microgrids. IEEE Power Energy Mag 2007; 5: 78-94

[8] Arcos-Aviles D, Pascual J, Guinjoan F, Marroyo L, Sanchis P, Marietta M.P. Low complexity energy management strategy for grid profile smoothing of a residential grid-connected microgrid using generation and demand forecasting. Applied Energy 205 (2017) 69-84

[9] Khodayar M.E. Rural electrification and expansion planning of off-grid microgrids The Electricity Journal 30 (2017) 68-74

[10] Robert F.C, Gopalan S. Low cost, highly reliable rural electrification through a combination of grid extension and local renewable energy generation. Sustainable Cities and Society 42 (2018) 344-354 
[11] Dinçer F. The analysis on photovoltaic electricity generation status, potential and policies of the leading countries in solar energy. Renewable and Sustainable Energy Reviews 15 (2011) 713-720

[12] Leary J, While A, Howell R. Locally manufactured wind power technology for sustainable rural electrification. Energy Policy 43 (2012) 173-83

[13] Notton G, Diaf S, Stoyanov L. Hybrid photovoltaic/wind energy systems for remote locations. Energy Procedia 6 (2011) 666-677

[14] APP, Africa Progress Panel. Africa Lights, Power, Action: Electrifying Africa (2017)

[15] United Nations. Transforming our world: The 2030 agenda for sustainable development (2015)

[16] Narula, K, Nagai, Y, Pachauri S. The role of decentralized distributed generation in achieving universal rural electrification in South Asia by 2030. Energy Policy 47 (2012) 345-357

[17] López-González A, Domenech B, Ferrer-Martí L. Lifetime, cost and fuel efficiency in diesel projects for rural electrification in Venezuela. Energy Policy 121 (2018a) 152-161

[18] Moner-Girona M, Bódis K, Morrissey J, Kougias I, Hankins M, Huld T, Szabó S. Decentralized rural electrification in Kenya: Speeding up universal energy access. Energy for Sustainable Development 52 (2019) 128146

[19] Akella AK, Sharma MP, Saini RP. Optimum utilization of renewable energy sources in a remote area. Renewable \& Sustainable Energy Reviews 11 (2007) 894-908

[20] Lambert TW, Hittle DC. Optimization of autonomous village electrification systems by simulated annealing. Sol Energy 68 (2000) 121-32

[21] Domenech B, Ferrer-Martí L, Pastor R. Hierarchical methodology to optimize the design of stand-alone electrification systems for rural communities considering technical and social criteria. Renewable and Sustainable Energy Reviews 51 (2015) 182-196

[22] Howells M, Rogner H, Strachan N, Heaps C, Huntington H, Kypreos S, Hughes A, Silveira S, DeCarolis J, Bazillian M, Roehrl A. OSeMOSYS: The Open Source Energy Modeling SystemAn introduction to its ethos, structure and development Energy Policy 39 (2011) 5850-5870

[23] Hoffmann M. M. Reiner Lemoine Institut (RLI). Offgridders github reprository. 2019a. Available at: https://github.com/smartie2076/offgridders. Accessed 2019 Jul 1.

[24] Kumar A, Mohanty P, Palit D, Chaurey A. Approach for standardization of off-grid electrification projects. Renewable and Sustainable Energy Reviews 13 (2009) 1946-1956

[25] Rahman M.M., Paatero J.V, Lahdelma R. Evaluation of choices for sustainable rural electrification in developing countries: A multicriteria approach. Energy Policy 59 (2013) 589-599

[26] Olówósejéke S, Leahy P, Morrison A.P. A practical approach for increased electrification, lower emissions and lower energy costs in Africa. Sustainable Futures 2 (2020) 100022

[27] Moreira F, Portugal M, Ribeiro F, Frias C. Government attenuation of institutional inefficiencies in capital markets: influence on the financial performance of Brazilian electricity distribution companies. Utilities Policy 60 (2019) 100940

[28] Ilskog E. Indicators for assessment of rural electrification-An approach for the comparison of apples and pears. Energy Policy 36 (2008) 2665-73 
[29] Yadoo A, Cruickshank $\mathrm{H}$. The role for low carbon electrification technologies in poverty reduction and climate change strategies: a focus on renewable energy minigrids with case studies in Nepal, Peru and Kenya. Energy Policy 42 (2012) 591-602

[30] Lillo P, Ferrer-Martí L, Fernández-Baldor Á, Ramírez B. A new integral management model and evaluation method to enhance sustainability of renewable energy projects for energy and sanitation services. Energy for Sustainable Development 29 (2015) 1-12

[31] López-González A, Domenech B, Ferrer-Martí L. Formative evaluation of sustainability in rural electrification programs from a management perspective: A case study from Venezuela. Renewable and Sustainable Energy Reviews 95 (2018b) 95-109

[32] Alarcon-Rodriguez A, Ault G, Galloway S. Multi-objective planning of distributed energy resources: A review of the state-of-the-art. Renewable and Sustainable Energy Reviews 14 (2010) 1353-1366

[33] Savic D. Single-objective vs. multi-objective optimization for integrated decision support. In: Proceedings of the first biennial meeting of the international environment modeling and software society 1 (2007) 7-12

[34] Keller S, Naciri S, Nejmi A, Dos Ghali J. Simulation-based decision support tool for electrification of isolated areas using a network with multiple renewable sources. In: Proceedings of international conference on clean electrical power 2007

[35] Cherni JA, Dyner I, Henao F, Jaramillo P, Smith R, Olade R. Energy supply for sustainable rural livelihoods. A multi-criteria decision-support system. Energy Policy 35 (2007) 1493-504

[36] Rojas-Zerpa J.C, Yusta J.M. Application of multicriteria decision methods for electric supply planning in rural and remote areas. Renewable and Sustainable Energy Reviews 52 (2015) 557-571

[37] IEA-PVPS, IEA - Photovoltaic Power Systems Program. PV for rural electrification in developing countriesprogramme design, planning and implementation. IEA PVPS REPORT T9-05 (2003), Paris, France

[38] Bhandari R, Saptalena L.G, Kusch W. Sustainability assessment of a micro hydropower plant in Nepal. Energy, Sustainability and Society (2018) 8:3

[39] Pramangioulis D, Atsonios K, Nikolopoulos N Rakopoulos D, Grammelis P, Kakaras E. A Methodology for Determination and Definition of Key Performance Indicators for Smart Grids Development in Island Energy Systems. Energies 2019, 12, 242

[40] Schäfer M, Kebir N, Neumann K. Research needs for meeting the challenge of decentralized energy supply in developing countries. Energy for Sustainable Development 15 (2011) 324-329

[41] Wang J-J, Jing Y-Y, Zhang C-F, Zhao J-H. Review on multi-criteria decision analysis aid in sustainable energy decision-making. Renewable and Sustainable Energy Reviews 13 (2009) 2263-2278

[42] Georgopoulou E, Lalas D, Papagiannakis L. A multicriteria decision aid approach for energy planning problems: the case of renewable energy option. European Journal of Operational Research 103 (1997) 38-54

[43] Ferrer-Martí L, Ferrer I, Sánchez E, Garfí M. A multi-criteria decision support tool for the assessment of household biogas digester programmes in rural areas. A case study in Peru. Renewable and Sustainable Energy Reviews 95 (2018) 74-83

[44] Hilpert S, Kaldemeyer C, Krien U, Günther S, Wingenbach C, Plessmann G. The Open Energy Modelling Framework (oemof) - A new approach to facilitate open science in energy system modelling. Energy Strategy Reviews 22 (2018) 16-25 
[45] Hoffmann M. M. Optimizing the Design of Off-Grid Micro Grids Facing Interconnection with an Unreliable Central Grid Utilizing an Open-Source Simulation Tool. Berlin (Germany): Technische Universität Berlin; 2019b

[46] Hoffmann M. M, Pelz S, Monés-Pederzini Ò, Andreottola M, Blechinger P. Overcoming the Bottleneck of Unreliable Grids: Increasing Reliability of Household Supply with Decentralized Backup Systems. J Sustain Res. 2020;2(1): e200009

[47] Bertheau P, Hoffmann M. M, Eras-Almeida A, Blechinger P. Assessment of micro grid potential in Southeast Asia based on the application of geospatial and micro grid simulation and planning tools. In: Sustainable solutions for remote areas in the tropics. Editor: Octoviano Ghandi, Dipti Srinivasan. (2020)

[48] Adefarati T, Bansal R.C, Jackson.J.Justo. Reliability and economic evaluation of a microgrid power system, 9th International Conference on Applied Energy, ICAE2017, 21-24, Cardiff, UK (2017)

[49] Chaurey A, Kandpal T.C. Assessment and evaluation of PV based decentralized rural electrification: An overview. Renewable and Sustainable Energy Reviews 14 (2010) 2266-2278

[50] Sovacool B.K, Kryman M, Laine E. Profiling technological failure and disaster in the energy sector: A comparative analysis of historical energy accidents. Energy 90 (2015) 2016-2027

[51] Gómez-Hernández D.F, Domenech B, Moreira J, Farrera N, López-González A, Ferrer-Martí L. Comparative evaluation of rural electrification project plans: A case study in Mexico. Energy Policy 129 (2019) 23-33

[52] McManus M.C. Environmental consequences of the use of batteries in low carbon systems: The impact of battery production. Applied Energy 93 (2012) 288-295

[53] Garfí M, Ferrer-Martí L, Velo E, Ferrer I. Evaluating benefits of low-cost household digesters for rural Andean communities. Renewable and Sustainable Energy Reviews 16 (2012) 575- 581

[54] Yu PL. A class of solution for group decision problem. Management Science 19 (1973) 936-946

[55] Zeleny M. Compromise programming. Multiple criteria decision making. University of South Carolina Press, Columbia (1973) 263-301

[56] Hashimoto A, Wu DA. A DEA-compromise programming model for comprehensive ranking. Journal of Operational Research of Japan (2004); 47: 73-81

[57] Cristóbal J.R. Multi-criteria decision-making in the selection of a renewable energy project in Spain: The VIKOR method. Renewable Energy 36 (2011) 498-502

[58] Blechinger P, Cader C, Bertheau P. Least-cost electrification modelling and planning - A case study for five Nigerian Federal States. Proceedings of the IEEE Vol. 107 No. 9 (2019b)

[59] IEA, International Energy Association. World energy outlook (2017)

[60] Arowolo W, Perez Y. Market reform in the Nigeria power sector: A review of the issues and potential solutions. Energy Policy 144 (2020) 111580

[61] Adhekpukoli E. The democratization of electricity in Nigeria. The Electricity Journal 31 (2018) 1-6

[62] Nnaji E, Adgidzi D, Dioha M Ewim D, Huan Z. Modelling and management of smart microgrid for rural electrification in sub-saharan Africa: The case of Nigeria. The Electricity Journal 32 (2019) 106672

[63] Cader, C. Comparison of Off-Grid Electrification versus Grid Extension: Influencing Parameters and the Role of Renewable Energy from a Geographic Point of View, English. Shaker Verlag GmbH, 2018, OCLC: 1048674727 
[64] Renewable Energy Potential (2014). Available at: https://www.get-invest.eu/marketinformation/nigeria/renewable-energy-potential/

[65] Olatomiwa L, Mekhilef S, Huda A, Ohunakin O. Economic evaluation of hybrid energy systems for rural electrification in six geo-political zones of Nigeria. Renewable Energy 83 (2015) 435-446

[66] World Bank. Minigrids in Nigeria. A case study of a promising market (2017)

[67] Brander M, Sood A, Wylie C, Haughton A, Lovell J. Electricity-specific emission factors for grid electricity. Econometrica (2011)

[68] World Bank. Nigeria Electrification Project (2020). Available online at: https://projects.worldbank.org/en/projects-operations/project-detail/P161885?lang=ar

[69] Gandini D, De Almeida A.T. Direct current microgrids based on solar power systems and storage optimization, as a tool for cost-effective rural electrification. Renewable Energy 111 (2017) 275-283 